San Jose State University

SJSU ScholarWorks

Master's Theses

Master's Theses and Graduate Research

Summer 2011

\title{
Numerical Investigation of Fundamental Physics for Flows over Expansion and Compression Corners
}

Freddy Ngo

San Jose State University

Follow this and additional works at: https://scholarworks.sjsu.edu/etd_theses

\section{Recommended Citation}

Ngo, Freddy, "Numerical Investigation of Fundamental Physics for Flows over Expansion and Compression Corners" (2011). Master's Theses. 4066.

DOI: https://doi.org/10.31979/etd.jbxx-6wuh

https://scholarworks.sjsu.edu/etd_theses/4066

This Thesis is brought to you for free and open access by the Master's Theses and Graduate Research at SJSU ScholarWorks. It has been accepted for inclusion in Master's Theses by an authorized administrator of SJSU ScholarWorks. For more information, please contact scholarworks@sjsu.edu. 
NUMERICAL INVESTIGATION OF FUNDAMENTAL PHYSICS

FOR FLOWS OVER EXPANSION AND COMPRESSION CORNERS

A Thesis

Presented to

The Faculty of the Department of Mechanical and Aerospace Engineering

San Jose State University

In Partial Fulfillment

of the Requirements for the Degree

Master of Science

by

Freddy Ngo

August 2011 
(C) 2011

Freddy Ngo

ALL RIGHTS RESERVED 
The Designated Thesis Committee Approves the Thesis Titled

NUMERICAL INVESTIGATION OF FUNDAMENTAL PHYSICS

FOR FLOWS OVER EXPANSION AND COMPRESSION CORNERS

by

Freddy Ngo

APPROVED FOR THE DEPARTMENT OF MECHANICAL AND AEROSPACE ENGINEERING

SAN JOSE STATE UNIVERSITY

August 2011

Dr. Periklis Papadopoulos Department of Mechanical and Aerospace Engineering

Dr. Nikos Mourtos Department of Mechanical and Aerospace Engineering

Dr. Sean Swei Department of Mechanical and Aerospace Engineering 


\begin{abstract}
NUMERICAL INVESTIGATION OF FUNDAMENTAL PHYSICS FOR FLOWS OVER EXPANSION AND COMPRESSION CORNERS
\end{abstract}

\author{
By Freddy Ngo
}

Oblique shocks and expansion waves are commonly found in aerospace applications such as wings and nozzles. These types of shocks change the properties of the flow, thus causing changes in the lift, drag, and/or heat transfer. Hypersonic flow is important to study as its impacts are significant. In this thesis, computational fluid dynamics (CFD) is utilized to characterize the physics of the flow. Parametric studies of the Mach number and turning angle were conducted. Simulations included both inviscid and viscous flows to demonstrate the effects of boundary layer on flow properties. The majority of the viscous flows were focused on the compression corner where the boundary layer started growing. The simulations produced evidence of flow separation at high turning angles. In addition, the boundary layer turned the flow upward at an angle, causing an oblique shock before reaching the corner. This phenomenon is known as shock-shock interaction. A turbulent flow developed a boundary layer faster than a laminar flow and can delay the separation of the flow. In general, the boundary layer can offset the properties of the flow, and a part of this study was performed to obtain the percentage difference and then use it as the correction factor for the offset. 


\section{Table of Contents}

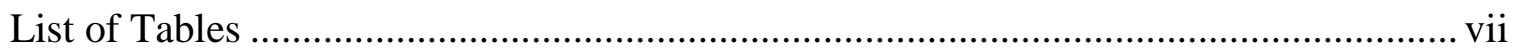

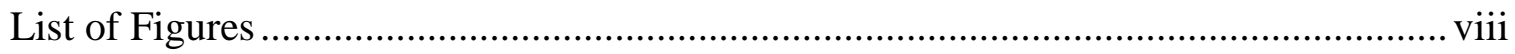

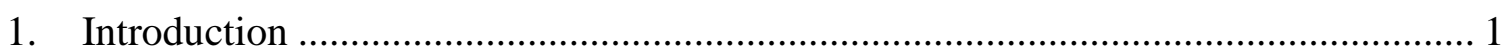

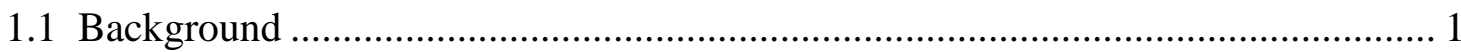

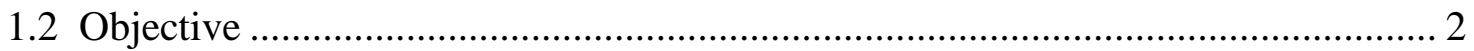

1.3 Previous Work

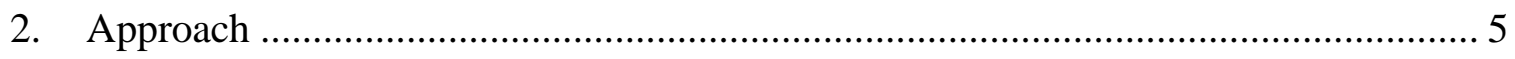

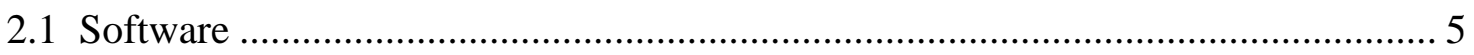

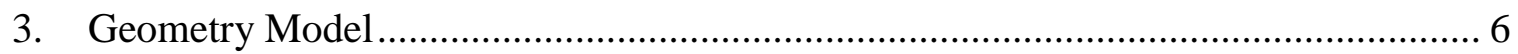

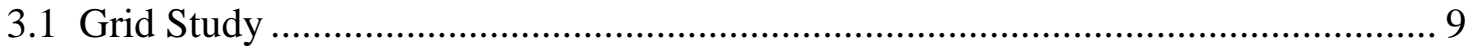

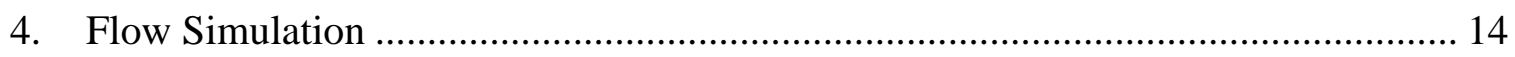

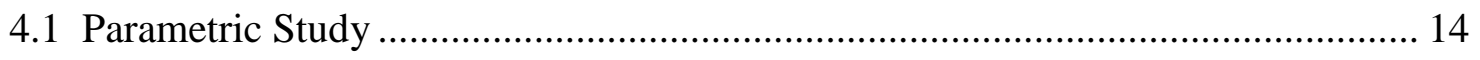

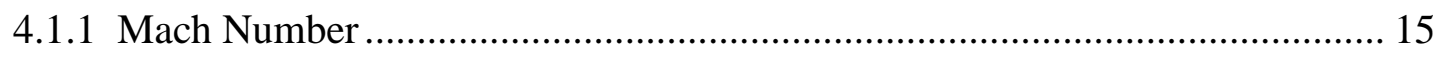

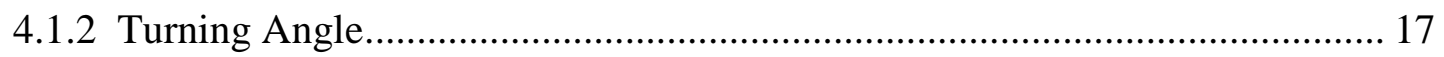

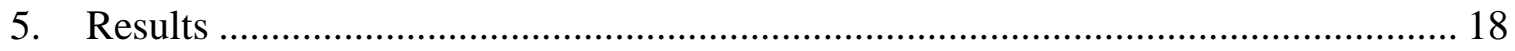

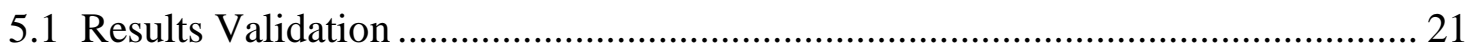

5.1.1 Compression Corners ………………………………............................... 21 


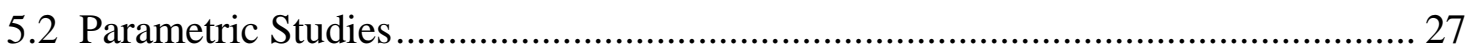

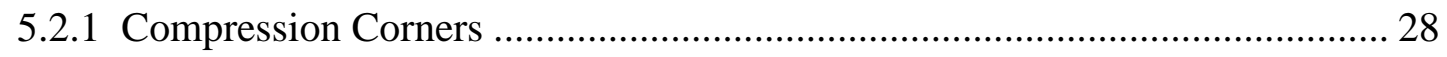

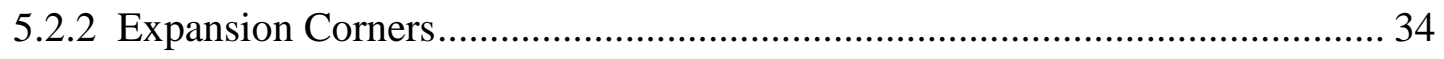

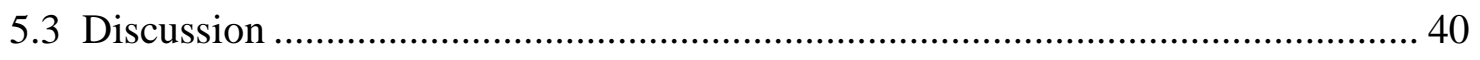

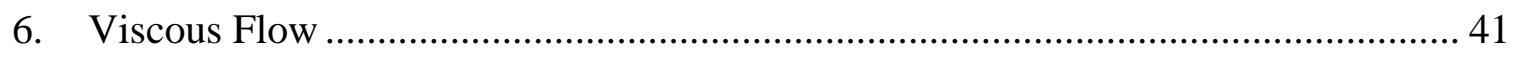

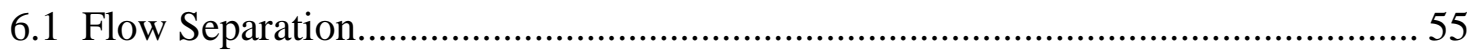

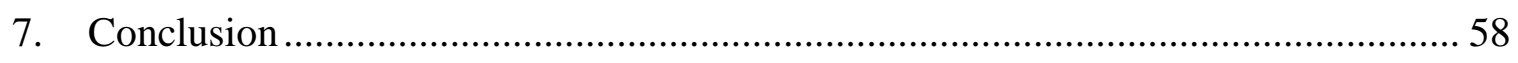

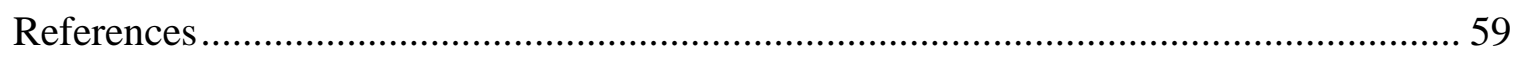




\section{List of Tables}

Table 1 - Velocity table with respect to Mach number................................................ 16

Table 2 - After-shock data for different turning angles ............................................ 43

Table 3 - After-shock data for different Mach numbers ........................................... 46

Table 4 - Before-shock data for different turning angles........................................... 50

Table 5 - Before-shock data for different Mach numbers.......................................... 52 


\section{List of Figures}

Figure 1 - Compression corner with $\theta$ turning angle ................................................. 6

Figure 2 - Sample result for compression corner........................................................ 7

Figure 3 - Expansion corner with $\theta$ turning angle ...................................................... 8

Figure 4 - Sample result for expansion wave........................................................... 8

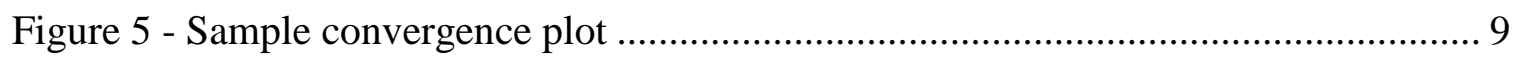

Figure 6 - Grid comparison for compression corner results .......................................... 10

Figure 7 - Grid comparison for compression corner for grid models ............................... 11

Figure 8 - Grid comparison for expansion corner results ........................................... 12

Figure 9 - Grid comparison for expansion corner for grid models .................................. 13

Figure 10 - Geometries with $\theta$ turning angle ........................................................... 17

Figure 11 - Mach 5 with $5^{\circ}$ compression corner results ................................................. 19

Figure 12 - Mach 5 with $5^{\circ}$ expansion corner results ...................................................... 20

Figure 13 - Extracted results of Mach 5, $5^{\circ}$ compression corner.................................... 23

Figure 14 - Extracted results of Mach 5, $5^{\circ}$ expansion corner......................................... 26

Figure 15 - Parametric study of Mach number of compression corners for Mach number

Figure 16 - Parametric study of Mach number of compression corners for pressure ....... 29

Figure 17 - Parametric study of Mach number of compression corners for temperature. 30

Figure 18 - Parametric study of turning angle of compression corners for Mach number31

Figure 19 - Parametric study of turning angle of compression corners for pressure ......... 32

Figure 20 - Parametric study of turning angle of compression corners for temperature .. 33 
Figure 21 - Parametric study of Mach number of expansion corners for Mach number.. 34

Figure 22 - Parametric study of Mach number of expansion corners for pressure 35

Figure 23 - Parametric study of Mach number of expansion corners for temperature ..... 36

Figure 24 - Parametric study of turning angle of expansion corners for Mach number ... 37

Figure 25 - Parametric study of turning angle of expansion corners for pressure ........... 38

Figure 26 - Parametric study of turning angle of expansion corners for temperature ...... 39

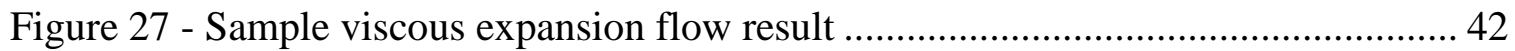

Figure 28 - Wave angle plot for different turning angles ....................................... 44

Figure 29 - After-shock percentage difference plot for different turning angles............. 45

Figure 30- Wave angle plot for different Mach numbers ........................................ 47

Figure 31 - After-shock percentage difference plot for different Mach numbers............ 48

Figure 32 - Before-shock percentage difference plot for different turning angles .......... 51

Figure 33 - Before-shock percentage difference plot for different Mach numbers .......... 53

Figure 34 - Viscous (top) and inviscid (bottom) flow comparison................................ 54

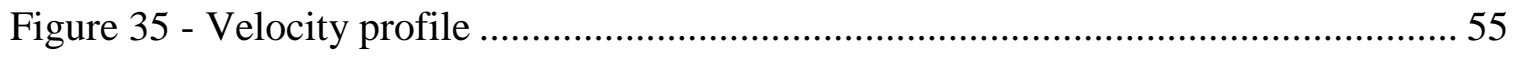

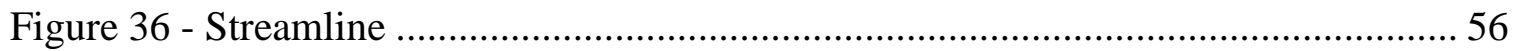

Figure 37 - Comparison of turbulent (top) and laminar (bottom) boundary layer........... 57

Figure 38 - Laminar flow's separation region (zoomed) ......................................... 57 


\section{Introduction}

\subsection{Background}

Most aircraft and nozzles have sharp edges or corners. A compression corner is like a hill for the air flow to climb. When the flow reaches a compression corner, an oblique shock is generated. An expansion corner, on the other hand, resembles a downward slope. When the flow reaches an expansion corner, several expansion waves emanated from the corner, allowing the flow to expand isentropically. The flow can be used as a metaphor for traffic, and the air particles can be viewed as cars. Going uphill is slower than going downhill. During slow traffic, the cars behind can catch up with the cars in front. During fast traffic, the cars in front can accelerate to abandon the cars behind. How these cars affect each other is the aim of this investigation. The creation of a shock wave, which can be described as a strong disturbance, can change the properties of the flow, depending on the type of shock. These types of shocks are being studied for the applications of engine inlet design for supersonic airplanes and diffuser design in supersonic wind tunnels (Anderson, 2004). A single oblique shock or expansion wave is easy to study. In practical applications, viscosity can alter the flow properties, and multiple shocks or a combination of different types of shock is common. A good practical application of multiple shocks is the internal flow through a scramjet engine, where the flow undergoes many oblique shocks simultaneously and experiences many expansion waves afterward. The properties of the flow change after each shock; 
therefore, it is important to understand the fundamental physics of the oblique shock and expansion wave in order to understand how the flow behaves.

\subsection{Objective}

The objective of this thesis was to study the fundamental physics behind the oblique shocks and expansion waves. The oblique shocks and expansion waves were modeled individually by using computational fluid dynamics (CFD) under different turning angles and Mach numbers. First, the flow was modeled as an inviscid flow to benchmark the data. Then viscosity was added to simulate a more practical application. The CFD results showed images of the properties of the flow at various locations.

\subsection{Previous Work}

An analysis of oblique shock waves incident on an interface between two different materials was performed by Loomis and Swift (2008). They developed numerical schemes to solve the problem of oblique shock scattering from the interface of two solid materials. The schemes were derived from a series of equations used to solve for all flow variables, given the incident shock state and angle. The authors also used a numerical simulation involving two-dimensional Eulerian continuum mechanical codes to validate their numerical schemes. Their analytical and numerical methods were found to be in agreement. 
Li (2007) performed a three-dimensional stability analysis on shock reflection. The shock strength was kept constant, and the incident angle was treated as the independent variable. Li found that the reflection angle increased as the incident angle increased. The focus of his work was to find the critical angle where the shock became detached. The shock became unstable when the incident angle was larger than the critical incident angle. However, for an oblique shock, there are both weak and strong shocks, and Li's work involved only the weak shock.

Pasha and Sinha (2008) studied oblique shock with an interacting boundary. They used Reynolds-averaged Navier-Stokes (RANS) equations to compute shock wave/turbulent boundary layer interaction. These equations also predicted separation bubble size and the heat transfer rate at reattachment. The authors showed that the shock interaction with turbulent fluctuation dampened the amplification of turbulent kinetic energy. As a result, they added the shock unsteadiness modification to correct damping. Pasha and Sinha also did experiments on the flat plate at three different incident angles undergoing shock waves created by the shock generator. They found that the strength of the shock increased as the incident angle increased, creating stronger interaction with the boundary layer. With the shock unsteadiness modification, the model prediction was greatly improved.

Heat transfer in the region of the incidence of an oblique shock wave has also been studied (Borovoi, Egorov, Skuratov, \& Struminkaya, 2005). The heat transfer coefficient was found to increase abruptly at the end of the separation region induced by 
the shock wave. The peak of the heat flux was also attained. A blunted-plate surface was studied. The blunting was used to reduce the heat flow and the maximum temperature to the leading edge. At the same time, the blunting was limited to avoid decreasing the performance of the aircraft. The analysis was done both experimentally and numerically. The equations that were used were two-dimensional (2D) equations for the motion of viscous gas for three different Mach numbers. The laminar flow was numerically simulated by solving 2D Navier-Stokes equations. The analysis showed that blunting the body caused an increase in the heat transfer, which was created by the transition at the end of the separation from the laminar state to the turbulent state.

The studies above have shown what has been done in the past for the oblique shocks or the expansion waves. However, analyses of how these shocks change are not investigated. This investigation is different from the previous studies because it not only shows how the flow is affected by the shocks but also how the Mach number and turning angle affect the flow. 


\section{Approach}

The investigation was done by performing parametric studies of the Mach number from 5 to 15 and the turning angle from $5^{\circ}$ to $15^{\circ}$. The flow was modeled as inviscid to see how these parameters affect the flow. Moreover, to study the impacts of the boundary layer, the flow was modeled as turbulent. First, before the flows can be simulated, the geometries have to be created, which were done by using CFD-GEOM. The geometries consisted of flows on a flat plate reaching a compression or expansion corner at different angles with different Mach numbers. Then the geometries were transferred to CFD-FASTRAN-GUI for simulation. The simulations were performed by specifying the problem type, the fluid model, and the flow conditions. Once the simulations were done, the results were viewed by using CFD-VIEW. The results were displayed as images of the flow with color schemes to indicate the values of the flow properties.

\subsection{Software}

- Platform: Microsoft Windows 7

- ESI-CFD 2009

- CFD-GEOM Version 2009.0.1.3

- CFD-FASTRAN-GUI Version 2009.0.3

- CFD-VIEW Version V2009.0.5 


\section{Geometry Model}

The geometries were modeled by using CFD-GEOM. To simulate the flows over a compression or an expansion corner, the geometries were modeled as 2-dimensional flat plates connected to a compression or an expansion corner.

An example of a compression corner model is shown in Figure 1. The area inside the model is referred as the computational domain, and the bottom contour of the shape is the compression corner. $\theta$ is the angle between the corner and the horizontal, also known as the turning angle. The areas before and after the shock are known to be uniform, so they do not need many grid points, whereas the area where the shock occurs should have more grid points to capture the shock. The shock is the area where the changes in the flow properties take place. The shock is a line from the beginning of the corner and extends at an angle known as the wave angle.

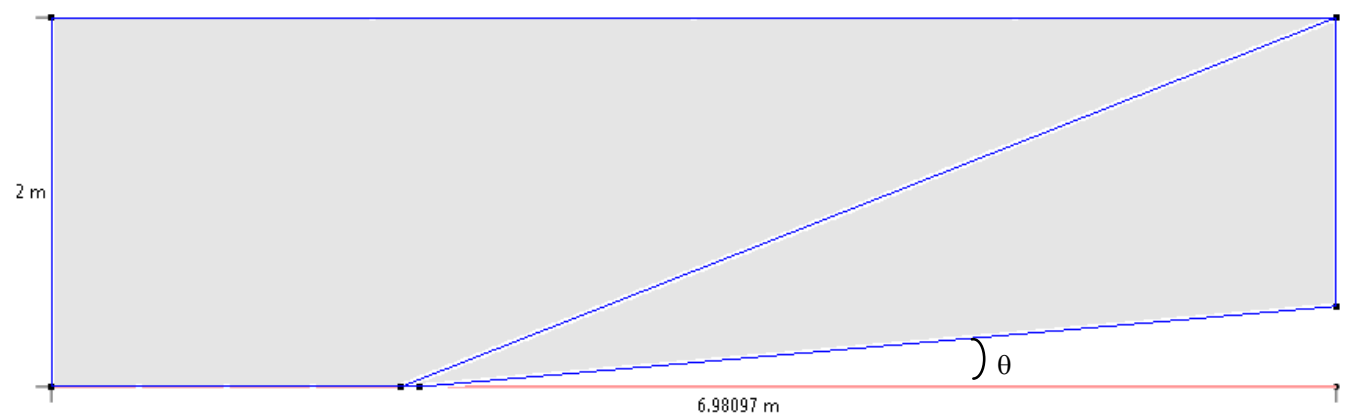

Figure 1 - Compression corner with $\theta$ turning angle

To strategically place the grid points, a rough estimate of the wave angle is needed. Figure 2 shows a sample result. $\beta$ is the wave angle, the line separating the flow 
before and after the shock. To sufficiently model the flow, the area around the wave line is where the grid points should be focused. Since the wave angle is a function of the Mach number and decreases as the Mach number increases, it is desired to allocate most of the grid points in the entire area behind the wave line. The area in front of the wave line has the minimum number of grid points since the flow is uniform before the shock.

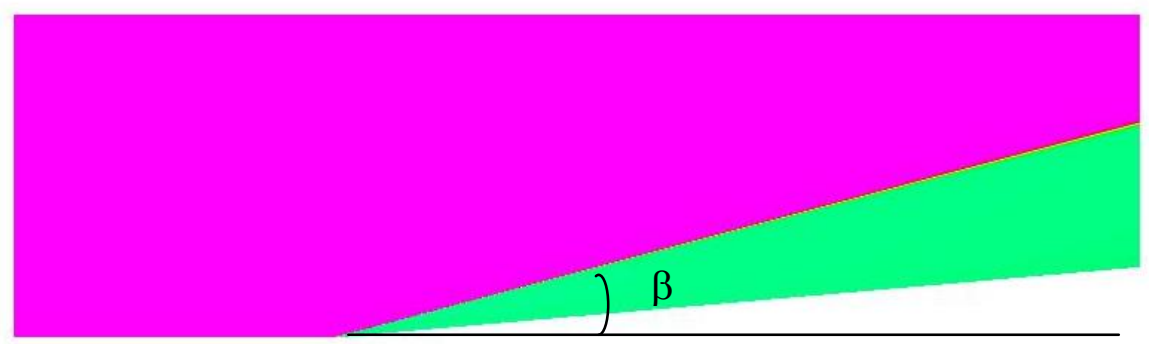

Figure 2 - Sample result for compression corner

The geometries for the expansion corner are similar to those of the compression corner. An example of an expansion corner is shown in Figure 3. The turning angle, $\theta$, is turning away from the flow instead of toward the flow like the compression corner. Likewise, the area is the flow, while the bottom contour is the shape of the expansion corner. The white lines represent the grids. Consequently, the pink area is the area where the grids are coarse, and the white area is the area where the grids are fine. Unlike the oblique shock, the area after the expansion wave is not uniform. Therefore, it needs more grid points. 


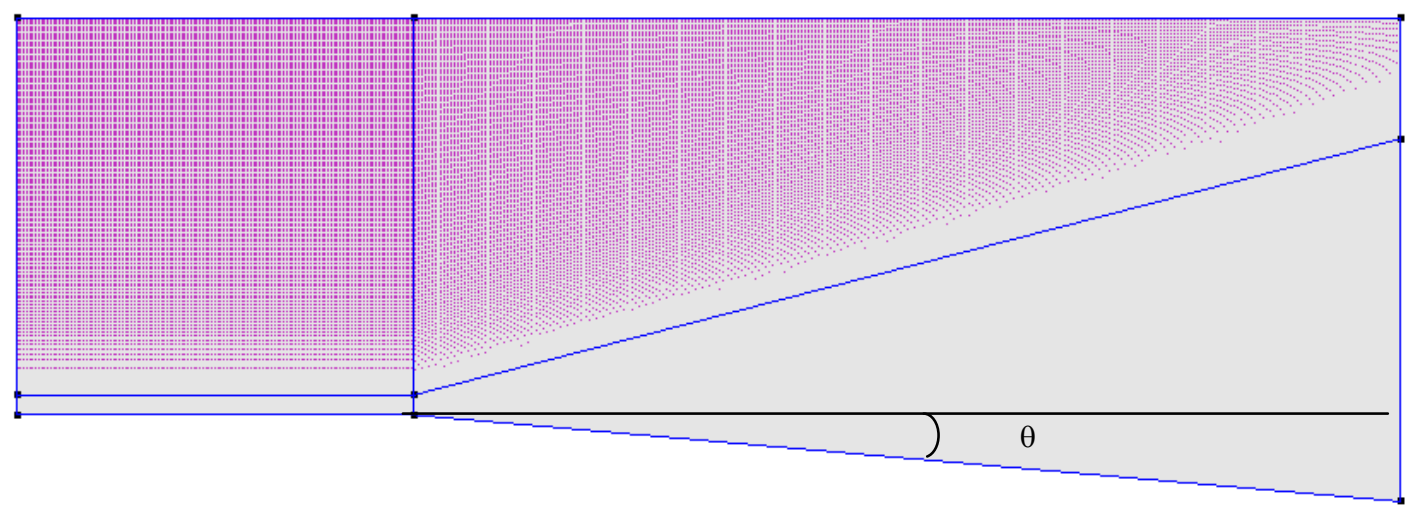

Figure 3 - Expansion corner with $\theta$ turning angle

Similar to the compression corners, the grid points are strategically allocated. A rough estimate of the wave angle is needed to divide the model. Likewise, Figure 4 provides the rough estimation of the wave angle $\beta$. The majority of the grid points are placed behind the wave line.

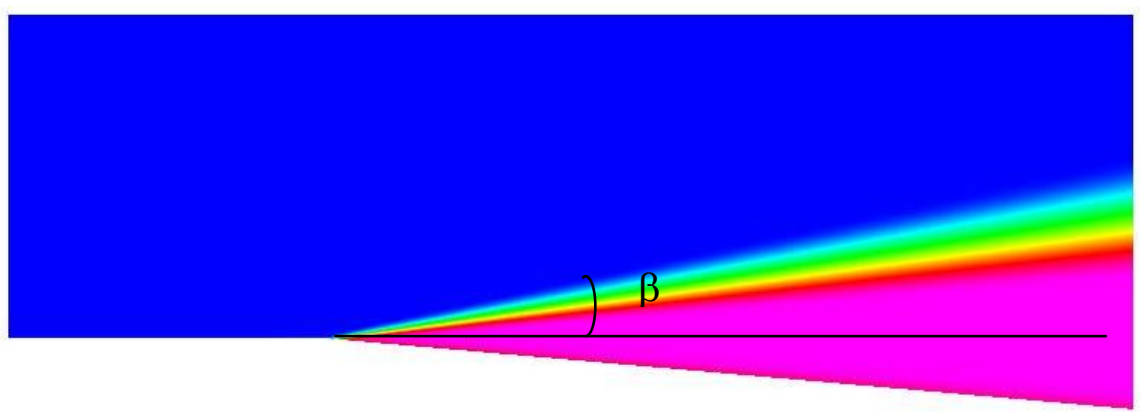

Figure 4 - Sample result for expansion wave 


\subsection{Grid Study}

The accuracy of the results depends on the convergence of the results. The convergence depends on the grids, how many points and how well they are allocated, and the number of iterations. Figure 5 is an example of the convergence plot. The lower value indicates the more convergent results. The residual value of 0.001 is the convergence criterion for this investigation. The residual value decreases as the iteration continues. The rate of change of the residual value depends on the quality of the model, the number of grid points, the flow model, and the conditions of the flow.

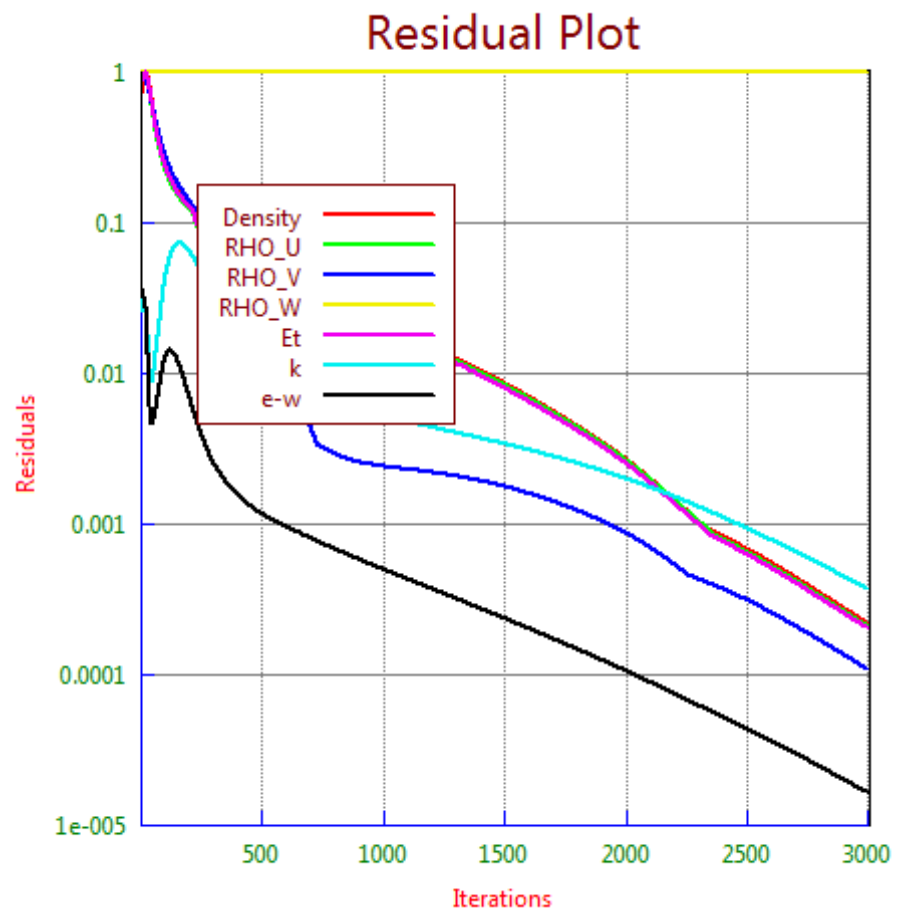

Figure 5 - Sample convergence plot 
Numerous simulation test cases had been done to obtain more accurate and refined results. Figure 6 compares the results of the Mach number of a fine grid and a coarse grid. The top figure contains the results of a high-resolution grid. It shows that the oblique shock is thin, corresponding to the theory. Unlike the bottom figure, the results are correct, but the shock appears to be thick and has a gradient. This error is primarily due to insufficient number of grid points. As a result, the grid points can greatly affect the results. The corresponding grids are shown in Figure 7.
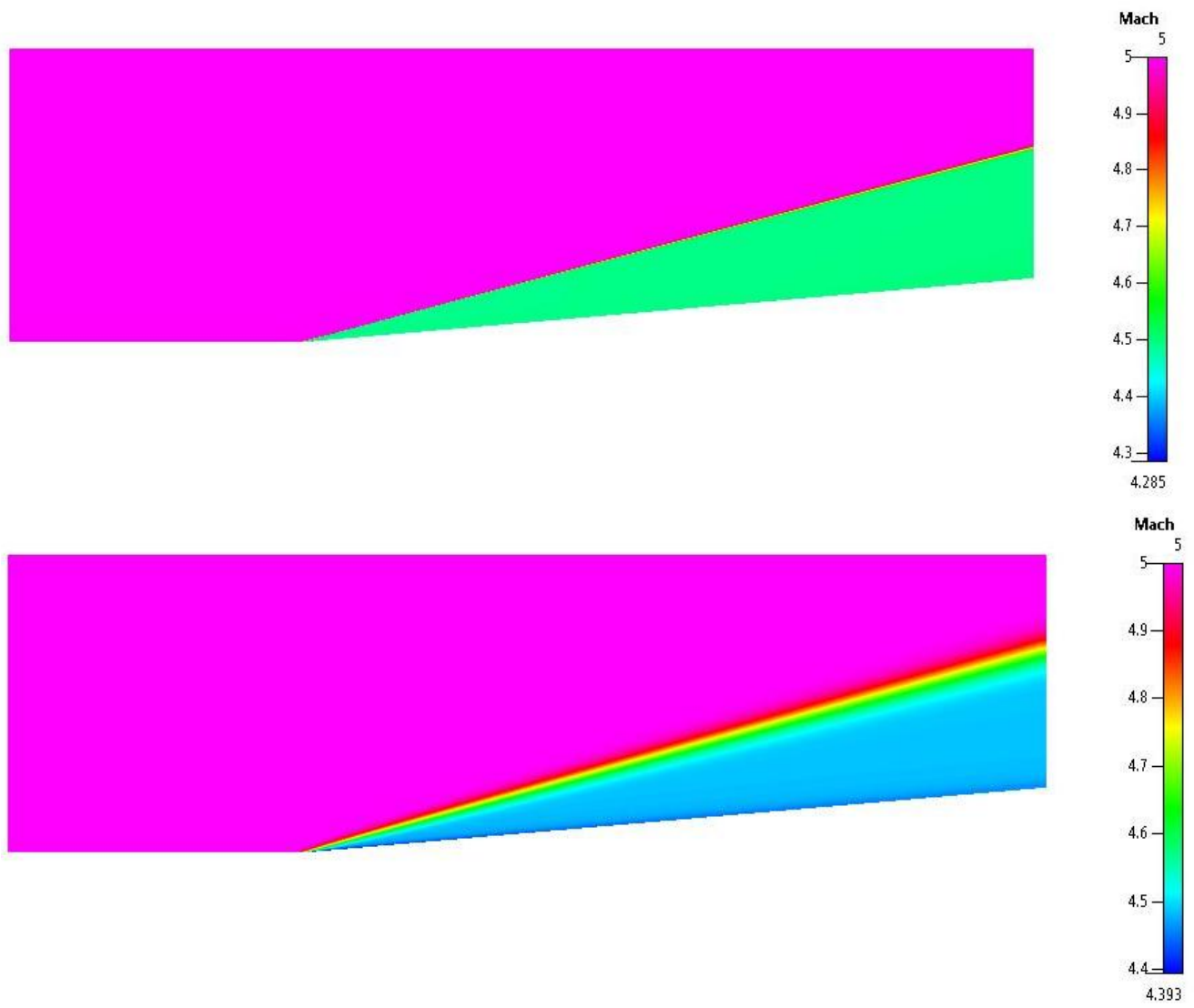

Figure 6 - Grid comparison for compression corner results 

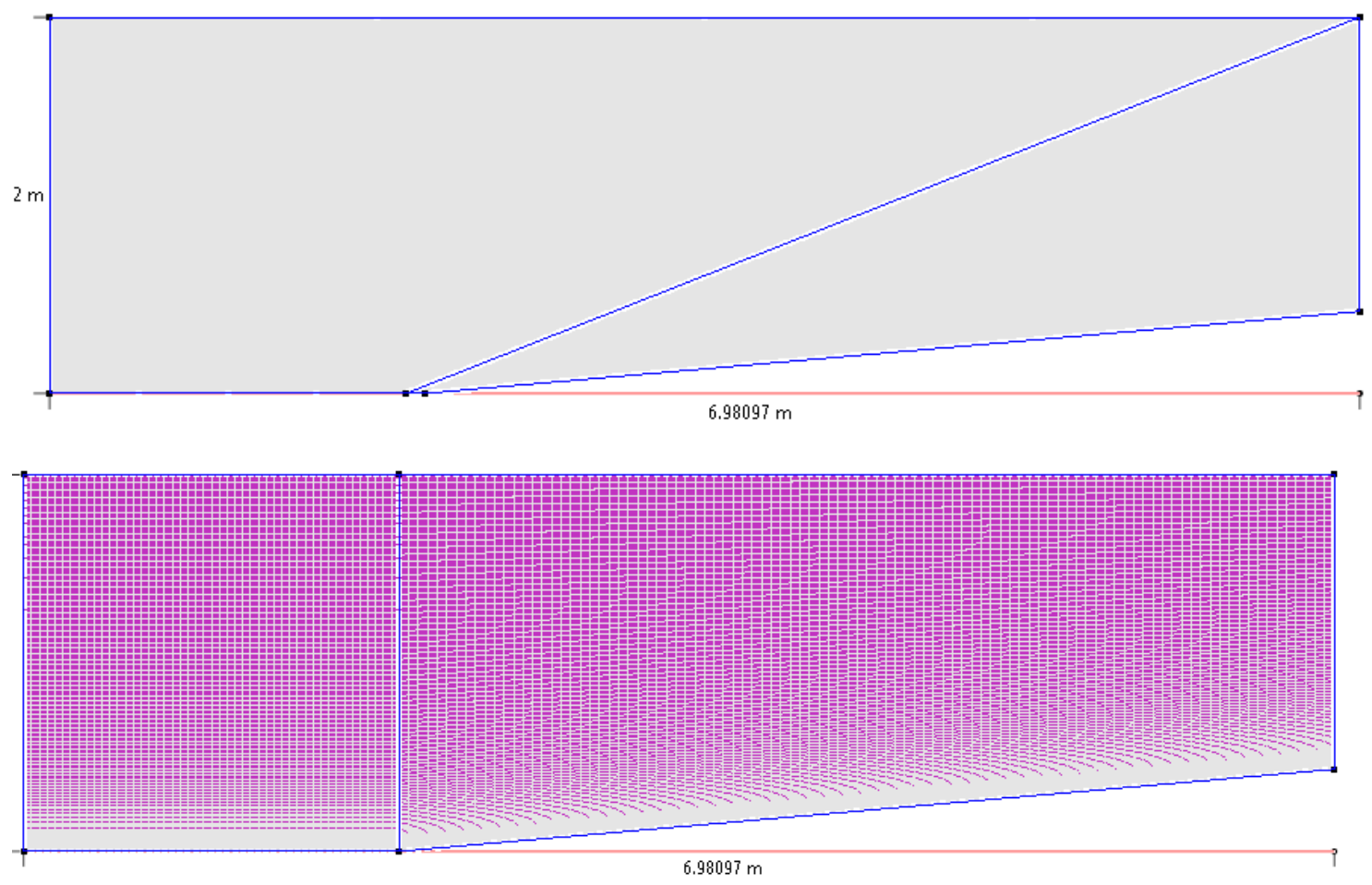

Figure 7 - Grid comparison for compression corner for grid models

The grids are not only different in the number of grid points but also the concentration of the grid points. The top figure not only has a greater number of grid points, but it is also more strategically allocated. It produces refined results with reduced simulation time. On the other hand, the bottom figure has many grid points that are placed in the uniform flow region. The extra grid points increase the simulation time but do not improve the results. Those grid points are wasted. The models have been refined progressively to improve the efficiency and the accuracy of the simulation. 
Similar to the compression corners, analyses of the expansion corners are also performed. Figure 8 compares the results of the expansion corner for two qualities of the grids. The refined grids produce a sharper image, thus, more accurate results, while the coarse grids produce a blurry image. This difference in the results is expected.
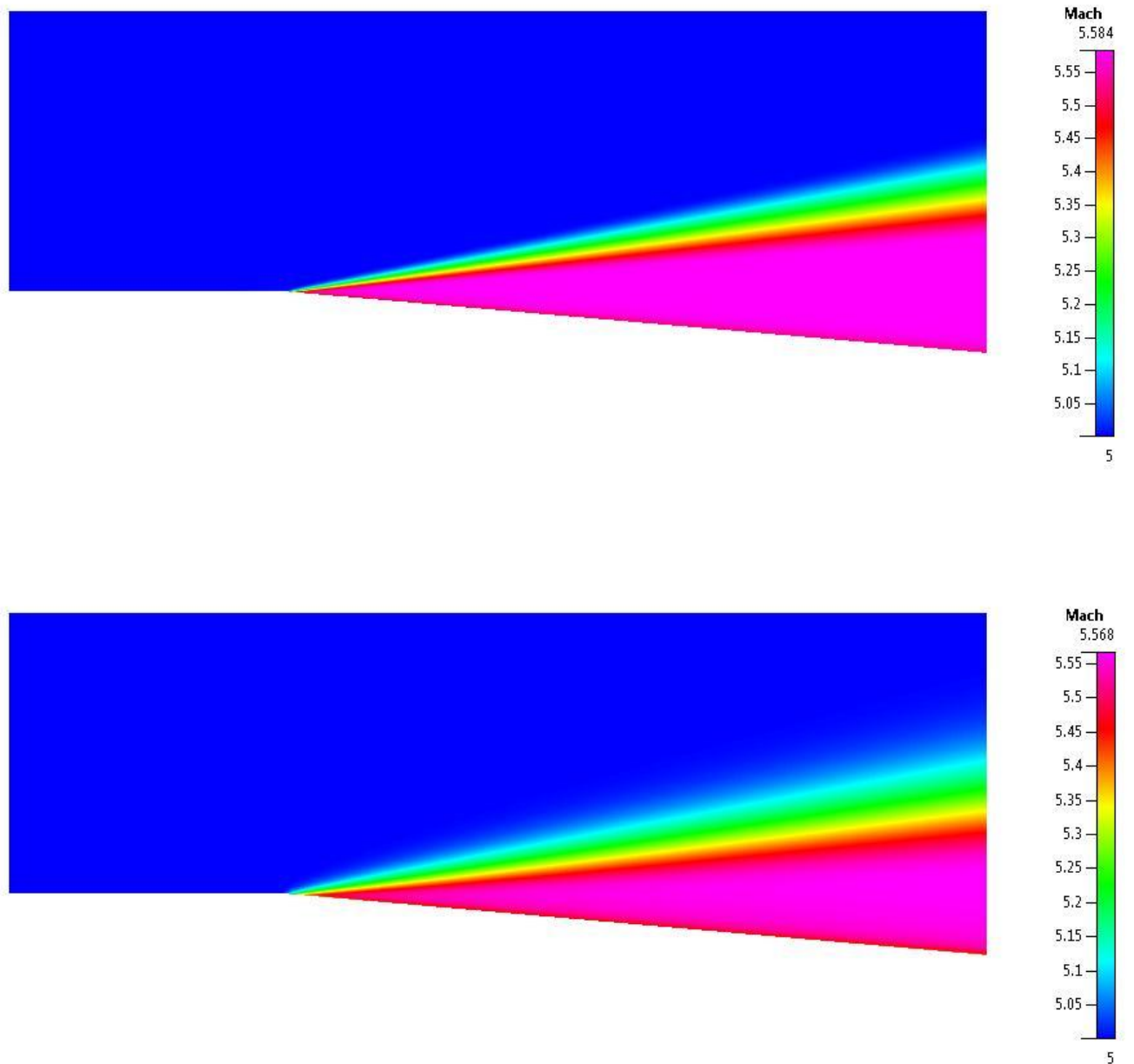

Figure 8 - Grid comparison for expansion corner results 
Figure 9 compares the qualities of the two grids. The top figure has more refined and strategically allocated grid points while the bottom figure has a simple, uncalculated grid distribution. As a result, the refined grids produce a sharper and more accurate image of the result.
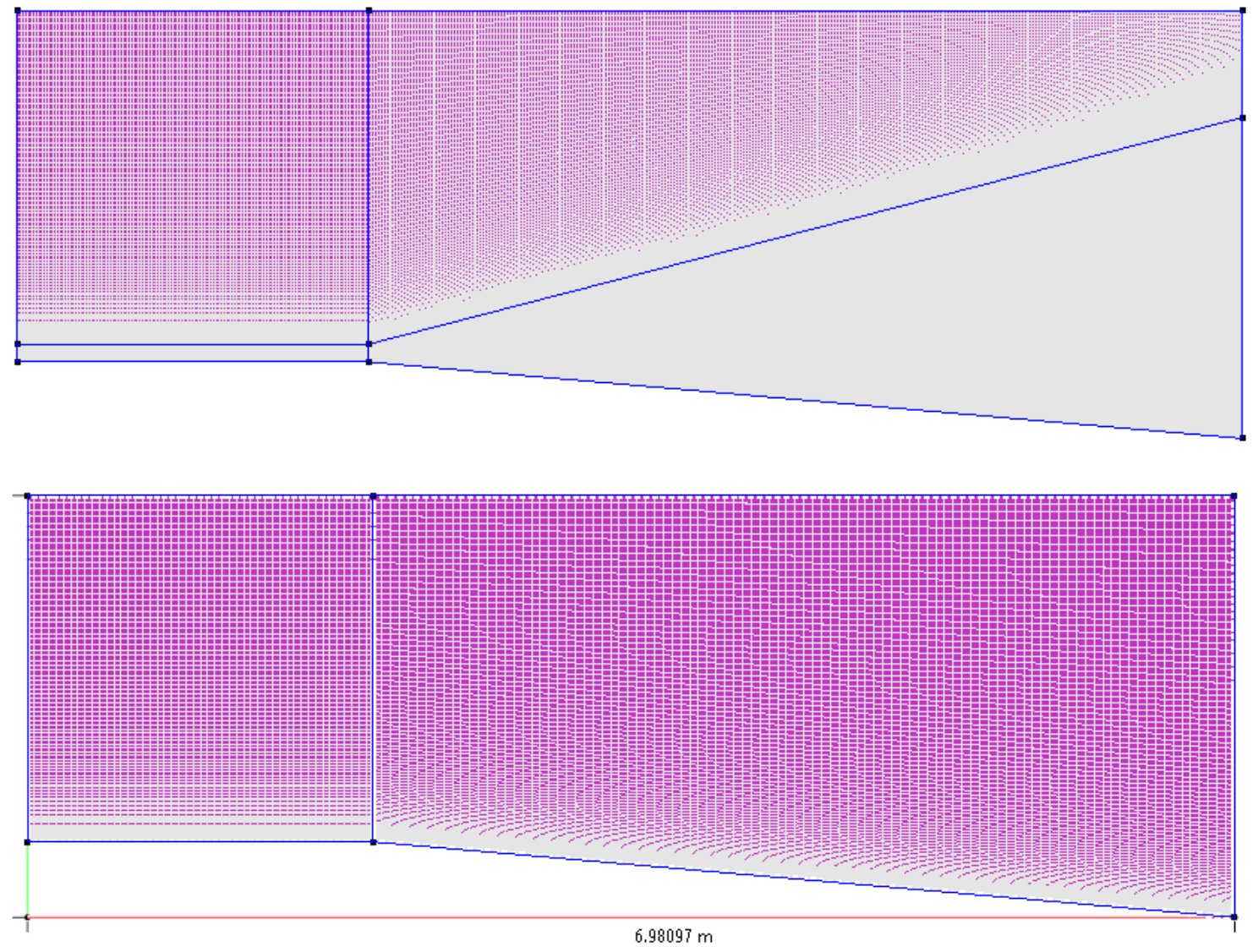

Figure 9 - Grid comparison for expansion corner for grid models 


\section{Flow Simulation}

The geometries were simulated by using CFD-FASTRAN-GUI. FASTRAN allows the input of the type of problem, the viscous model, the flow conditions, and the number of iterations. Inputting these parameters controls the type of flow, and different problems can be simulated by changing these parameters. Below is the list of properties for the flow simulation.

- Flow Type: Compressible Flow

- Gas Type: Ideal Gas

- $\quad$ Molecular Weight $=28.97 \mathrm{~g} / \mathrm{mol}$

$\circ \quad \gamma(\mathrm{Cp} / \mathrm{Cv})=1.4$

Viscous Model: Inviscid (Euler)

- Flow Conditions:

- Static Pressure $=101 \mathrm{kPa}($ atmospheric pressure $)$

- $\quad$ Static Temperature $=300 \mathrm{~K}$

\subsection{Parametric Study}

There are two control variables for the parametric study: the Mach number and the turning angle. The parametric study is performed by changing one variable at a time, while keeping every other condition constant. For example, to perform a parametric 
study on the Mach number, all the other conditions are kept constant, while the Mach number is changed.

\subsubsection{Mach Number}

The Mach number (M) depends on the freestream velocity. The Mach number is the ratio of the freestream velocity to the speed of sound. In FASTRAN, there is no input for Mach number, only for the horizontal and vertical velocities. To input the desired Mach number, calculations of the freestream velocity are needed. The freestream velocity is inputted as the horizontal velocity. Below are the calculations of the freestream velocity. The Mach number is ranged from 5 to 15 .

- $\mathrm{M}=\mathrm{U} / \mathrm{a}$

- $\mathrm{U}$ is freestream velocity $(\mathrm{m} / \mathrm{s})$

- a is speed of sound $(\mathrm{m} / \mathrm{s})$

$$
\text { - } \mathrm{a}=\sqrt{\gamma \mathrm{RT}}=347.2 \mathrm{~m} / \mathrm{s} \text { (constant) }
$$

Since the speed of sound, a, is constant, a function of the Mach number with respect to freestream velocity is created.

- $\mathrm{M}=\mathrm{U} / 347.2$

- $\mathrm{U}=347.2 \mathrm{M}$ 
Table 1 - Velocity table with respect to Mach number

\begin{tabular}{|r|r|}
\hline $\mathbf{M}$ & $\mathbf{U}(\mathbf{m} / \mathbf{s})$ \\
\hline 5 & 1736 \\
\hline 6 & 2083.2 \\
\hline 7 & 2430.4 \\
\hline 8 & 2777.6 \\
\hline 9 & 3124.8 \\
\hline 10 & 3472 \\
\hline 11 & 3819.2 \\
\hline 12 & 4166.4 \\
\hline 13 & 4513.6 \\
\hline 14 & 4860.8 \\
\hline 15 & 5208 \\
\hline & \\
\hline & \\
\hline & \\
\hline 15 & \\
\hline 13 & \\
\hline & \\
\hline
\end{tabular}

Table 1 is the velocity table for the corresponding Mach number. It is generated by substituting the desired values for M in Equation (2). To obtain the desired Mach number for the simulation, the corresponding velocity is inputted into FASTRAN. 


\subsubsection{Turning Angle}

The turning angle, $\theta$, depends on the geometries. The turning angle is the angle the corner makes with respect to the horizontal. In Figure 10, the turning angle is marked for clarity. The turning angle can be controlled by changing the geometries. The turning angle is ranged from $5^{\circ}$ to $15^{\circ}$.
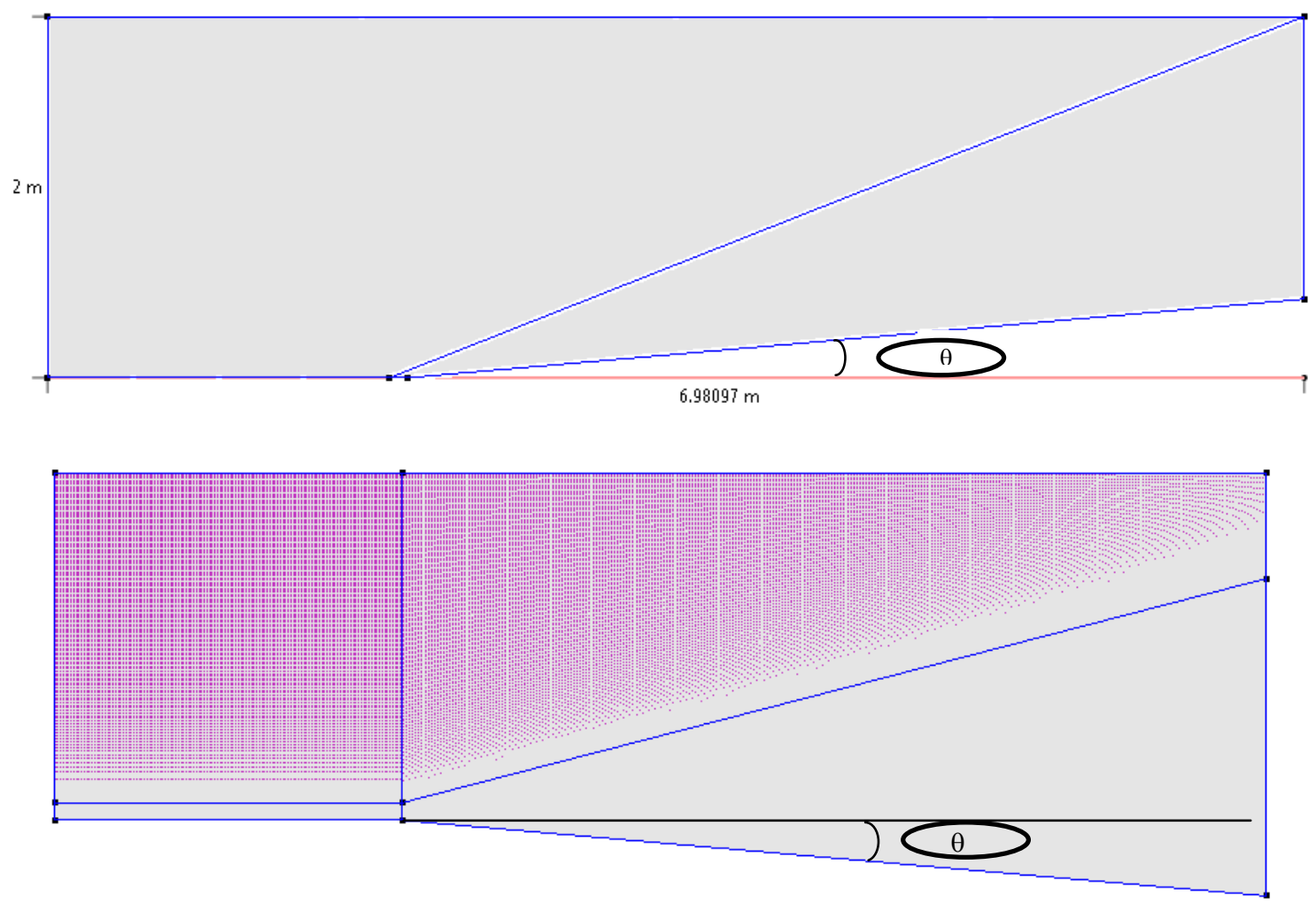

Figure 10 - Geometries with $\theta$ turning angle 


\section{Results}

After the simulations are finished by using CFD-FASTRAN-GUI, the results can be viewed by using CFD-VIEW. The results are the images of the flow before and after the shock in terms of space, consisting of the images of the compression corners and expansion corners. Analysis of the results is done by looking at the color schemes. At various regions of the flow, the colors are different, each representing the value of the properties. The different colors indicate the changes in the flow, either oblique shocks or expansion waves. The flow is uniform until it reaches the corner, the area where the shock occurs. Because the shock changes the properties of the flow, the color also changes. The location of the shock can be determined by looking at the section where the color changes.

In this investigation, the Mach number, pressure, and temperature are the three flow properties to be analyzed. Each flow property adheres to the color key at the right side of the image. The color key indicates the type of properties being viewed as well as their values. The results for each simulation consist of the images of the Mach number, pressure, and temperature. These images are grouped and viewed together. 

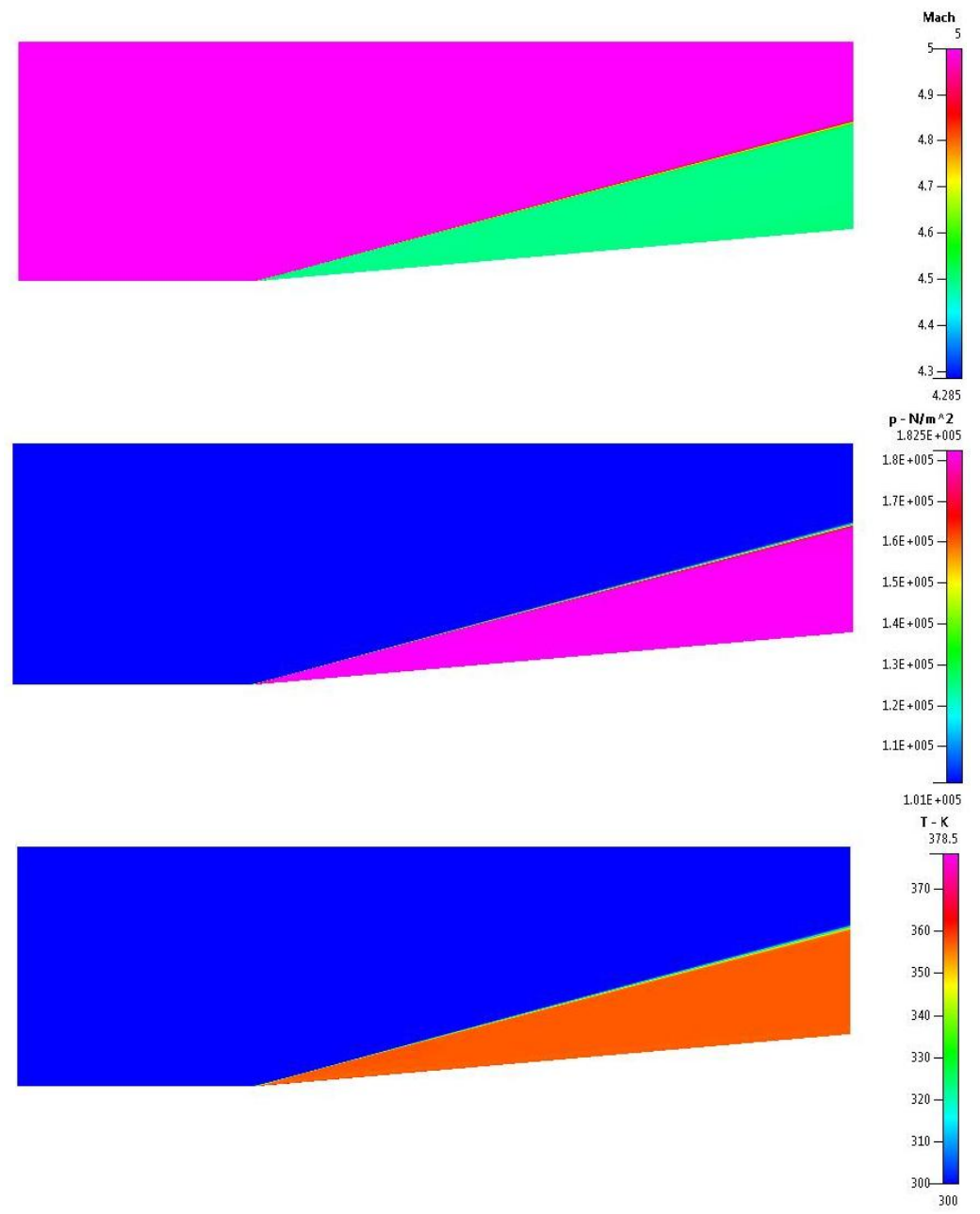

Figure 11 - Mach 5 with $5^{\circ}$ compression corner results

Figure 11 contains sample results for Mach 5 with $5^{\circ}$ turning angle compression corner. The images contain the Mach number $(\mathrm{M})$, temperature $(\mathrm{T})$, and pressure $(\mathrm{P})$ distribution. Based on these images, the Mach number is lower after the shock while the temperature and pressure are higher. 

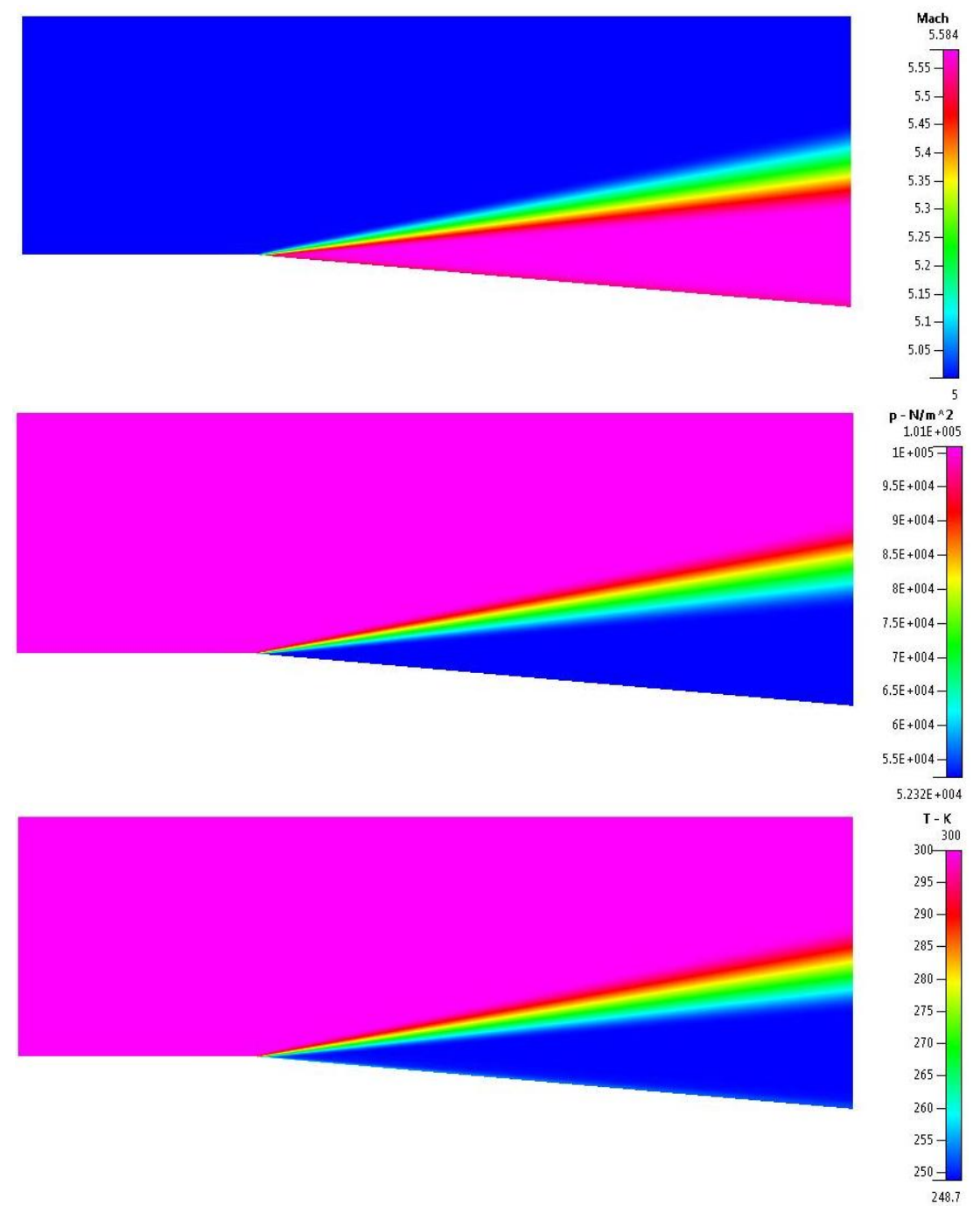

Figure 12 - Mach 5 with $5^{0}$ expansion corner results

Figure 12 contains sample results for Mach 5 with $5^{\circ}$ expansion corner. Contrary to the compression corner, the Mach number is higher while the temperature and pressure are lower. 


\subsection{Results Validation}

The computations, executed by a program, might contain errors. The results may follow the physics, but they may not be correctly calculated. It is important to verify the results to ensure that the geometries, the flow conditions, and the calculations are correctly set up. Below are samples of analytical work to validate the computational results. The cases being solved are the Mach $5,5^{\circ}$ turning angle compression corners, and expansion corners with $\mathrm{p}_{1}=101 \mathrm{kPa}, \mathrm{T}_{1}=300 \mathrm{~K}$.

\subsubsection{Compression Corners}

The wave angle, $\beta$, is calculated by using the $\theta-\beta-\mathrm{M}$ relation

$$
\tan \theta=2 \cot \beta\left[\frac{M_{1}^{2} \sin ^{2} \beta-1}{M_{1}^{2}(\gamma+\cos 2 \beta)+2}\right]
$$

where $M$ is the Mach number and $\theta$ is the turning angle. For $M=5, \theta=5^{\circ}, \beta$ is calculated to be $15^{\circ}$ by using Equation (3).

The freestream Mach number can be divided into normal and tangential components. Since the tangential component is preserved across the oblique shock, the changes across the oblique shock are determined by the normal component (Anderson, 2004).

$$
\mathrm{M}_{\mathrm{n} 1}=\mathrm{M}_{1} \sin \beta=5 \sin \left(15^{\circ}\right)=1.30
$$


Once that the Mach number normal to the wave has been found, the ratios of the properties after the shock can be found by using the normal shock relations.

$$
\begin{aligned}
& \mathrm{M}_{2}^{2}=\frac{1+[(\gamma-1) / 2] \mathrm{M}_{1}^{2}}{\gamma \mathrm{M}_{1}^{2}-(\gamma-1) / 2} \\
& \frac{p_{2}}{p_{1}}=1+\frac{2 \gamma}{\gamma+1}\left(\mathrm{M}_{1}^{2}-1\right) \\
& \frac{T_{2}}{T_{1}}=\left[1+\frac{2 \gamma}{\gamma+1}\left(\mathrm{M}_{1}^{2}-1\right)\right]\left[\frac{2+(\gamma-1) \mathrm{M}_{1}^{2}}{(\gamma+1) \mathrm{M}_{1}^{2}}\right]
\end{aligned}
$$

The Mach number after the shock, the pressure ratio, and the temperature ratio are calculated by using Equation (4), (5), and (6) for $\mathrm{M}=1.3$.

$$
\begin{aligned}
& \frac{p 2}{p 1}=1.805 \\
& \frac{T 2}{T 1}=1.191 \\
& \mathrm{M}_{\mathrm{n} 2}=0.7860
\end{aligned}
$$

The properties after the shock can be found by multiplying the initial properties by the corresponding ratios.

$$
\begin{aligned}
& \mathrm{p}_{2}=\frac{p 2}{p 1} \mathrm{p}_{1}=1.805(101 \mathrm{kPa})=182 \mathrm{kPa} \\
& \mathrm{T}_{2}=\frac{T 2}{T 1} \mathrm{~T}_{1}=1.191(300 \mathrm{~K})=357 \mathrm{~K} \\
& \mathrm{M}_{2}=\frac{M n 2}{\sin (\beta-\theta)}=\frac{0.7860}{\sin (15-5)}=4.53
\end{aligned}
$$


According to the analytical results, the Mach number, the pressure, and the temperature after the oblique shock are $4.53,182 \mathrm{kPa}$, and $357 \mathrm{~K}$, respectively. The next step is to extract the computational results from the images.
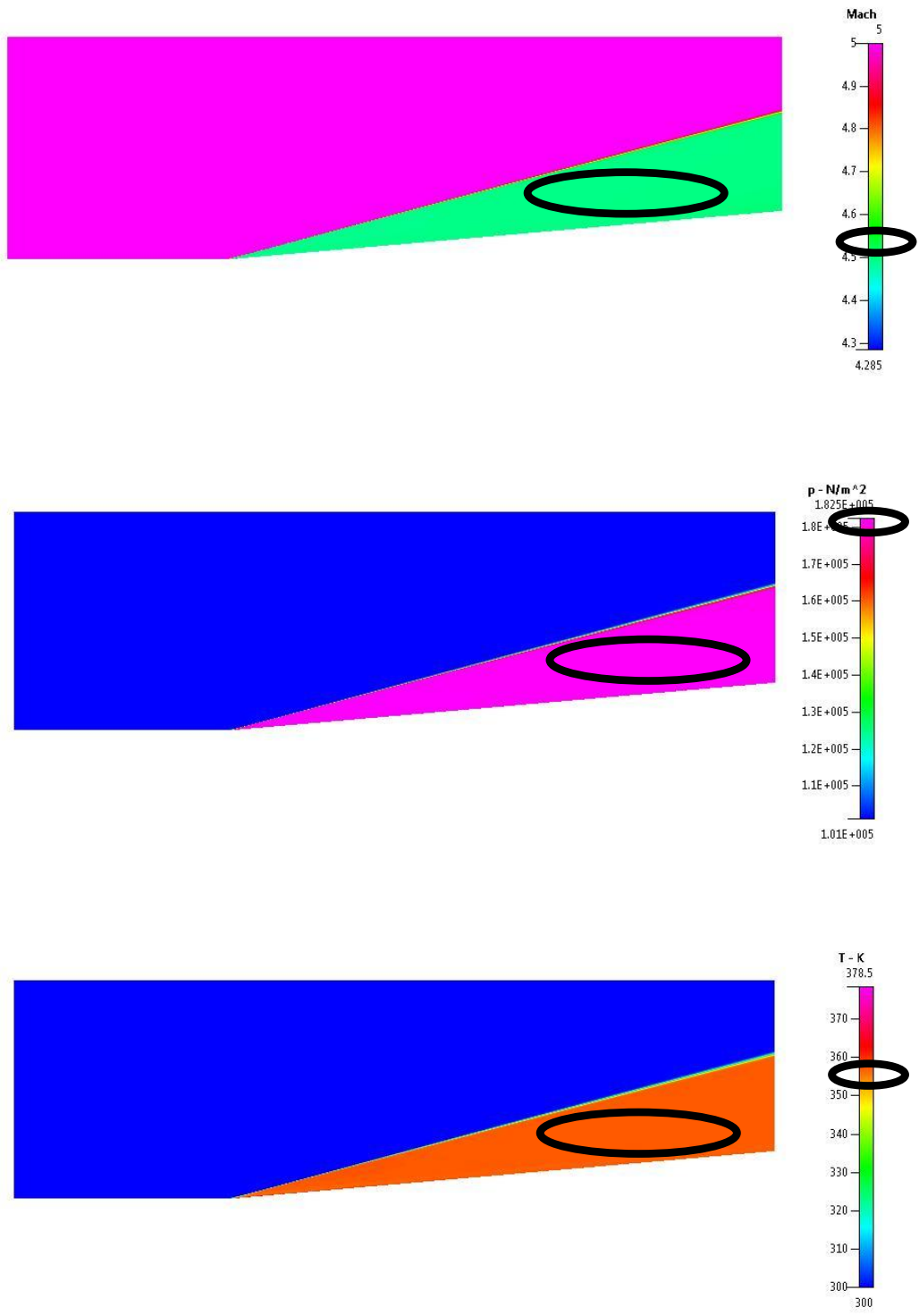

Figure 13 - Extracted results of Mach 5, $5^{\circ}$ compression corner 
Figure 13 contains the results of Mach 5 with $5^{\circ}$ compression corner. In the images, the circled regions are the regions after the shock where the flow becomes uniform again. The circled areas on the color keys indicate the corresponding values of the flow properties. Extracted from the images of the Mach number, pressure, and temperature, the estimations are $4.5,182.5 \mathrm{kPa}$, and $355 \mathrm{~K}$. Comparing the analytical results to the computational results, 4.5 to 4.53 Mach number, 182 to $182.5 \mathrm{kPa}$ pressure, and 357 to $355 \mathrm{~K}$ temperature, the results are close to each other with less than 5\% error. With such a low percentage error, the computational results are validated by the analytical results for the compression corner.

\subsubsection{Expansion Corner}

The expansion wave problem is calculated with the same conditions as the compression corner. The Prandtl-Meyer function is given by

$$
v(M)=\sqrt{\frac{\gamma+1}{\gamma-1}} \tan ^{-1} \sqrt{\frac{\gamma-1}{\gamma+1}\left(M^{2}-1\right)}-\tan ^{-1} \sqrt{M^{2}-1}
$$

With $\mathrm{M}=5, v_{1}$ is calculated to be $76.92^{\circ}$ with Equation (7).

$$
v_{2}=v_{1}+\theta=76.92+5=81.92^{\circ}
$$

Solving for $\mathrm{M}_{2}$ with the new $v_{2}$ by using Equation (7), $\mathrm{M}_{2}=5.6$. 
Since the expansion wave is isentropic, the properties after the expansion wave can be found by calculating the total to static ratio of the properties. These ratios are given by

$$
\begin{aligned}
& \frac{p_{0}}{p}=\left(1+\frac{\gamma-1}{2} M^{2}\right)^{\gamma /(\gamma-1)} \\
& \frac{T_{o}}{T}=1+\frac{\gamma-1}{2} M^{2}
\end{aligned}
$$

The total to static ratios for the pressure and the temperature of the Mach numbers before and after the expansion wave can be calculated by using Equation (8) and (9)

$$
\begin{aligned}
& \text { with } \mathrm{M}_{1}=5, \frac{p o 1}{p 1}=529.1, \frac{T o 1}{T 1}=6 \\
& \text { with } \mathrm{M}_{2}=5.6, \frac{p o 2}{p 2}=1037, \frac{T o 2}{T 2}=7.272
\end{aligned}
$$

Since expansion wave is isentropic, $\frac{p o 2}{p o 1}=1$

$$
\begin{aligned}
& \mathrm{p}_{2}=\frac{p 2}{p o 2} \frac{p o 2}{p o 1} \frac{p o 1}{p 1} \mathrm{p}_{1}=1 / 1037(1)(529.1)(101 \mathrm{kPa})=51.5 \mathrm{kPa} \\
& \mathrm{T}_{2}=\frac{T 2}{T o 2} \frac{T o 2}{T o 1} \frac{T o 1}{T 1} \mathrm{~T}_{1}=1 / 7.272(1)(6)(300 \mathrm{~K})=248 \mathrm{~K}
\end{aligned}
$$



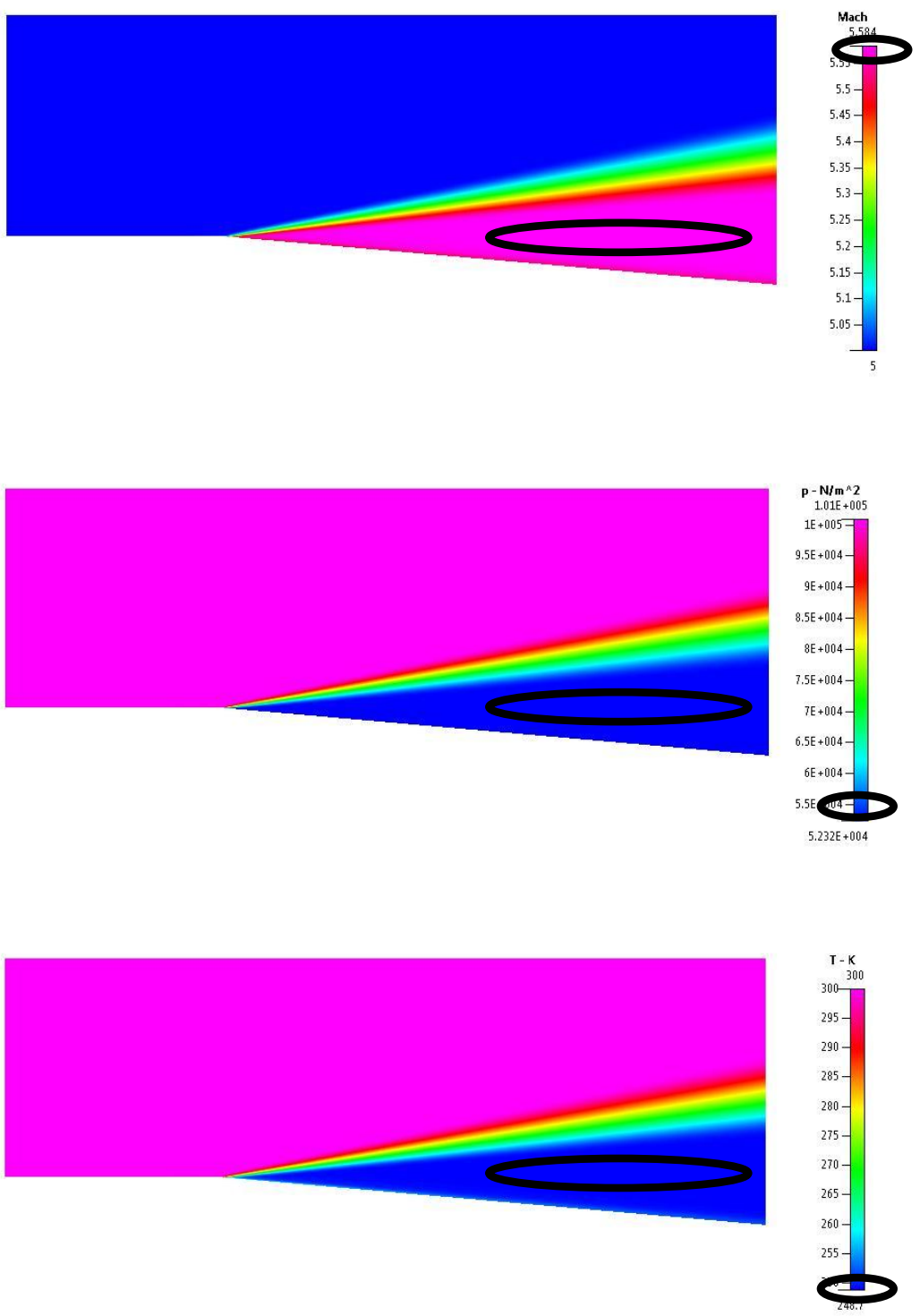

Figure 14 - Extracted results of Mach 5, $5^{\circ}$ expansion corner 
Extracted from Figure 14, the values for the Mach number, pressure, and temperature are estimated to be $5.586,52.32 \mathrm{kPa}$, and $248.7 \mathrm{~K}$, respectively. Comparing the analytical results with the computational results: 5.6 to 5.586 Mach number, 51.5 to $52.32 \mathrm{kPa}$ pressure, 248 to $248.7 \mathrm{~K}$ temperature. Again, the results are very close to each other with a minor percentage error. With such a minor percentage error, the computational results are validated by the analytical results. The expansion corner simulations are validated and correctly computed.

Both the compression corner and expansion corner are validated with analytical work. The percentage error is very small; the reasons for the error may be due to the significant digits and estimation. Overall, the results are kept within a good level of confidence. This concludes that the geometries and the flow conditions are correctly set up and the computations are convergent.

\subsection{Parametric Studies}

Once the effects of the oblique shocks and expansion waves have been studied, the next step is to analyze how changing the Mach number and the turning angle affect the shocks. Below are the comparisons of the results. They are grouped closely together to analyze the changes. The parametric studies are divided into four sections: two sections for the compression corners Mach number and turning angle and two sections for the expansion corners Mach number and turning angle. 


\subsubsection{Compression Corners}

The parametric studies of the Mach number and the turning angle are used to analyze the compression corners. There are two sections: one parametric study for the Mach number and one parametric study for the turning angle. The analyses consist of side-by-side images of the flow for the ease of comparison.

\subsubsection{Mach Number}

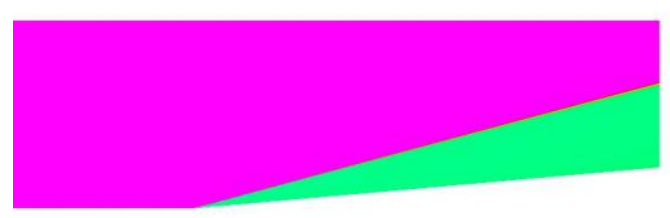

$$
M=5
$$

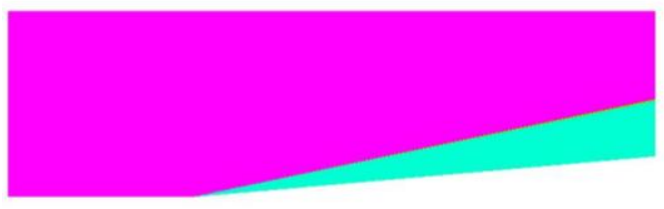

$$
\mathrm{M}=7
$$

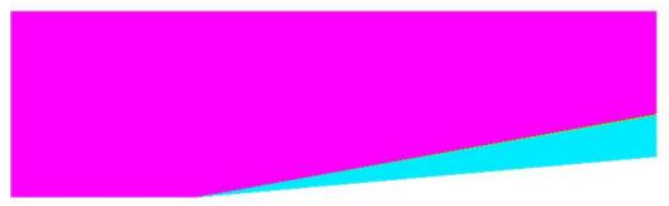

$$
M=9
$$

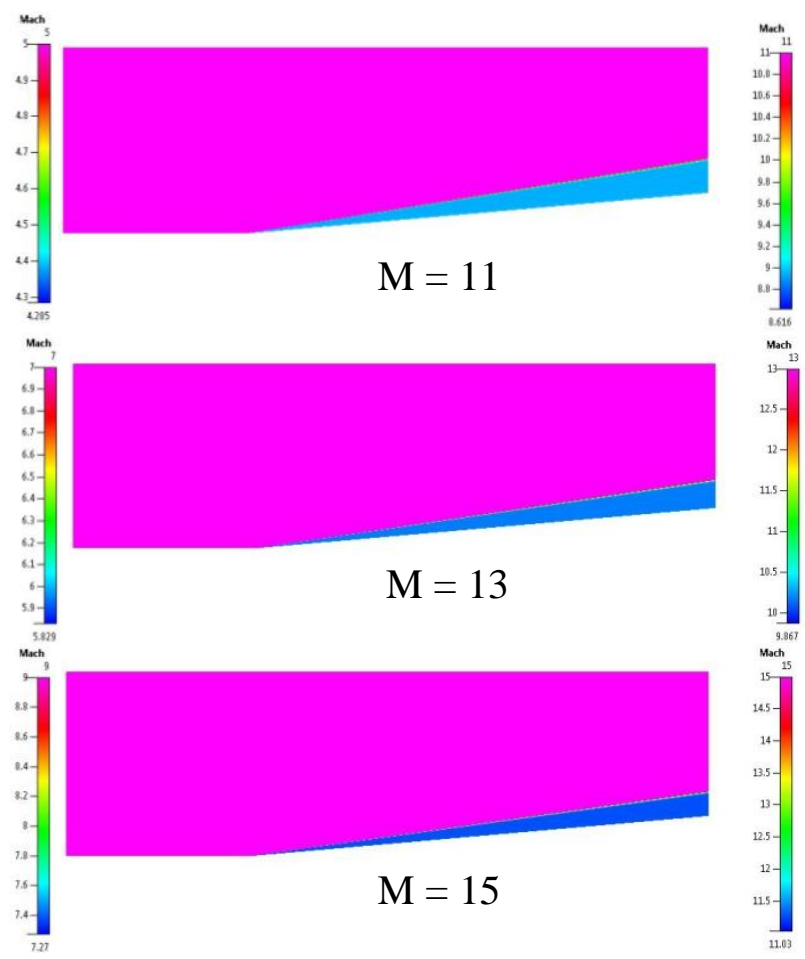

Figure 15 - Parametric study of Mach number of compression corners for Mach number

Figure 15 shows how the flow changes as the Mach number increases. The property being studied is the Mach number after the shock, along with the wave angle. 


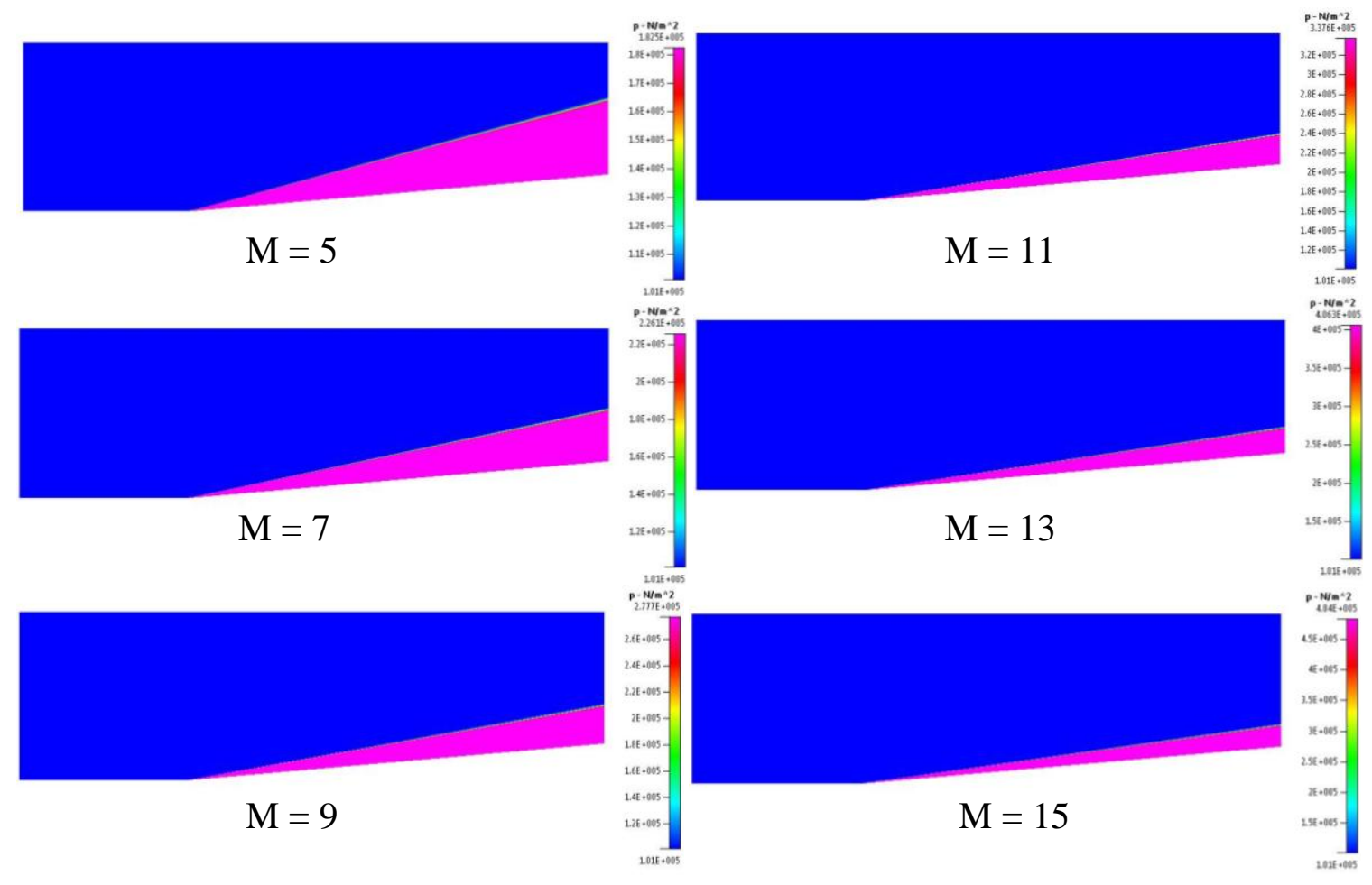

Figure 16 - Parametric study of Mach number of compression corners for pressure

Figure 16 shows how the pressure after the shock is affected as the Mach number increases. The strength of the shock increases as the Mach number increases. The pressure increases as the strength of the shock increases, so increasing the Mach number increases the pressure after the shock. 

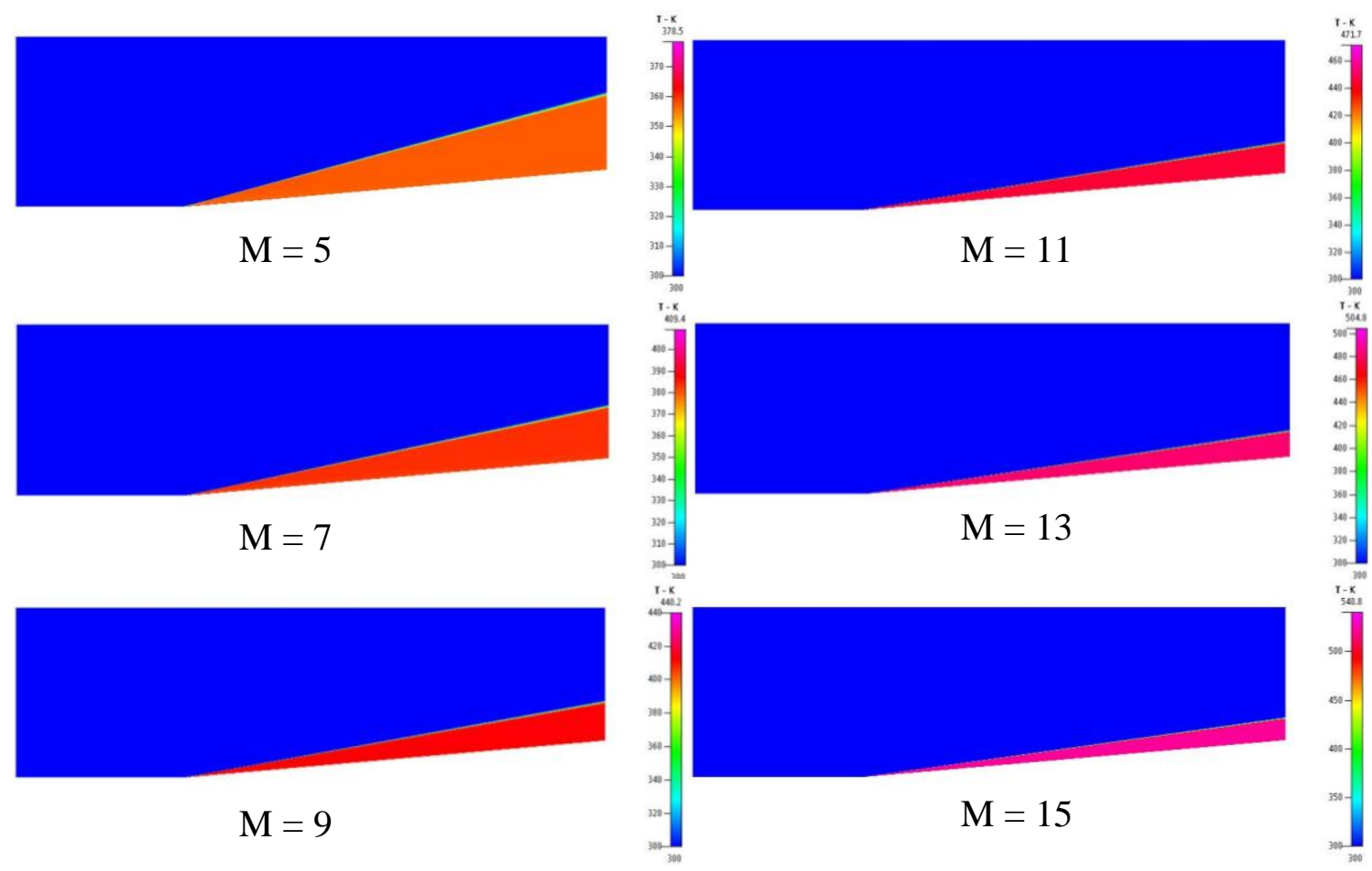

$\mathrm{M}=7$

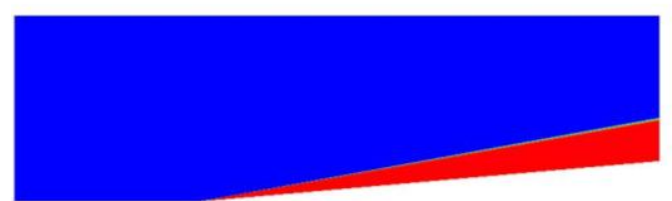

$\mathrm{M}=9$

$$
M=15
$$

Figure 17 - Parametric study of Mach number of compression corners for temperature

Figure 17 shows how the temperature after the shock is affected as the Mach number increases. Similar to the pressure, the temperature also increases as the Mach number increases.

For the same turning angle, the Mach number is varied from 5 to 15 in increments of 2 to analyze how the shock is affected. Based on Figure 15, Figure 16, and Figure 17, the wave angle decreases as the Mach number increases. The analysis corresponds to the $\theta-\beta$-M curves. As the Mach number approaches infinity, the wave angle, $\beta$, decreases to approach zero. Furthermore, increasing the Mach number increases the pressure and the temperature after the shock. 


\subsubsection{Turning Angle}
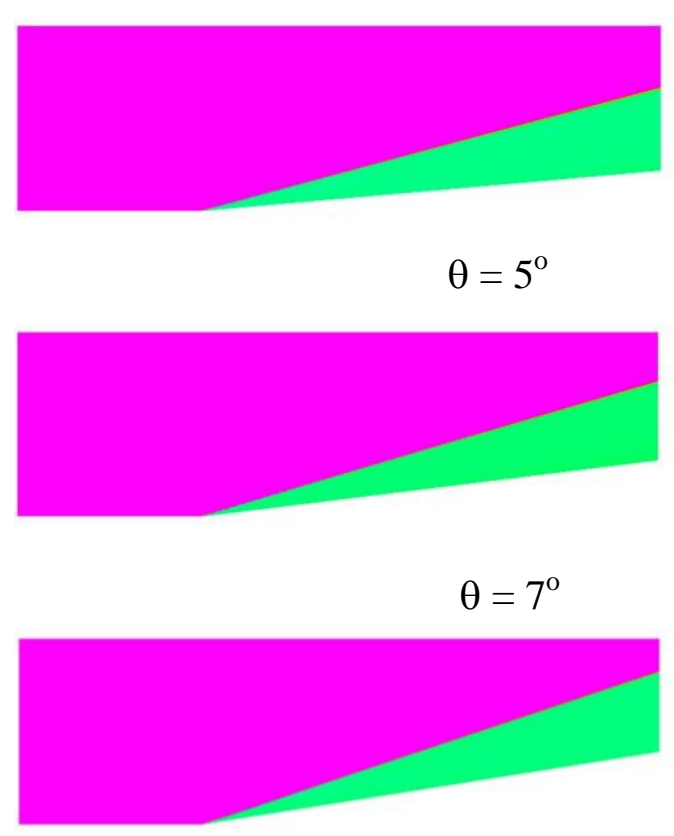

$$
\theta=9^{\circ}
$$

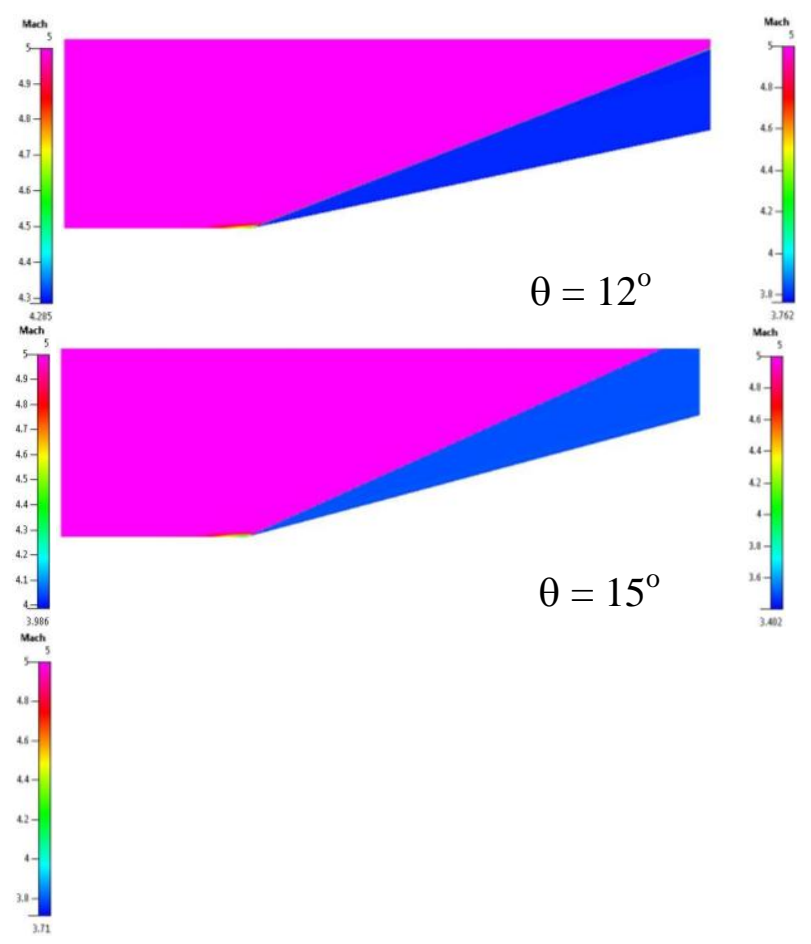

Figure 18 - Parametric study of turning angle of compression corners for Mach number

The parametric study of the turning angle is performed by keeping the Mach number constant at 5 while changing the turning angle. Figure 18 shows how the Mach number after the shock changes as the turning angle increases. A high turning angle produces a higher wave angle. Furthermore, the strength of the shock also increases as the turning angle increases. The Mach number after the shock decreases as the strength of the shock increases. 


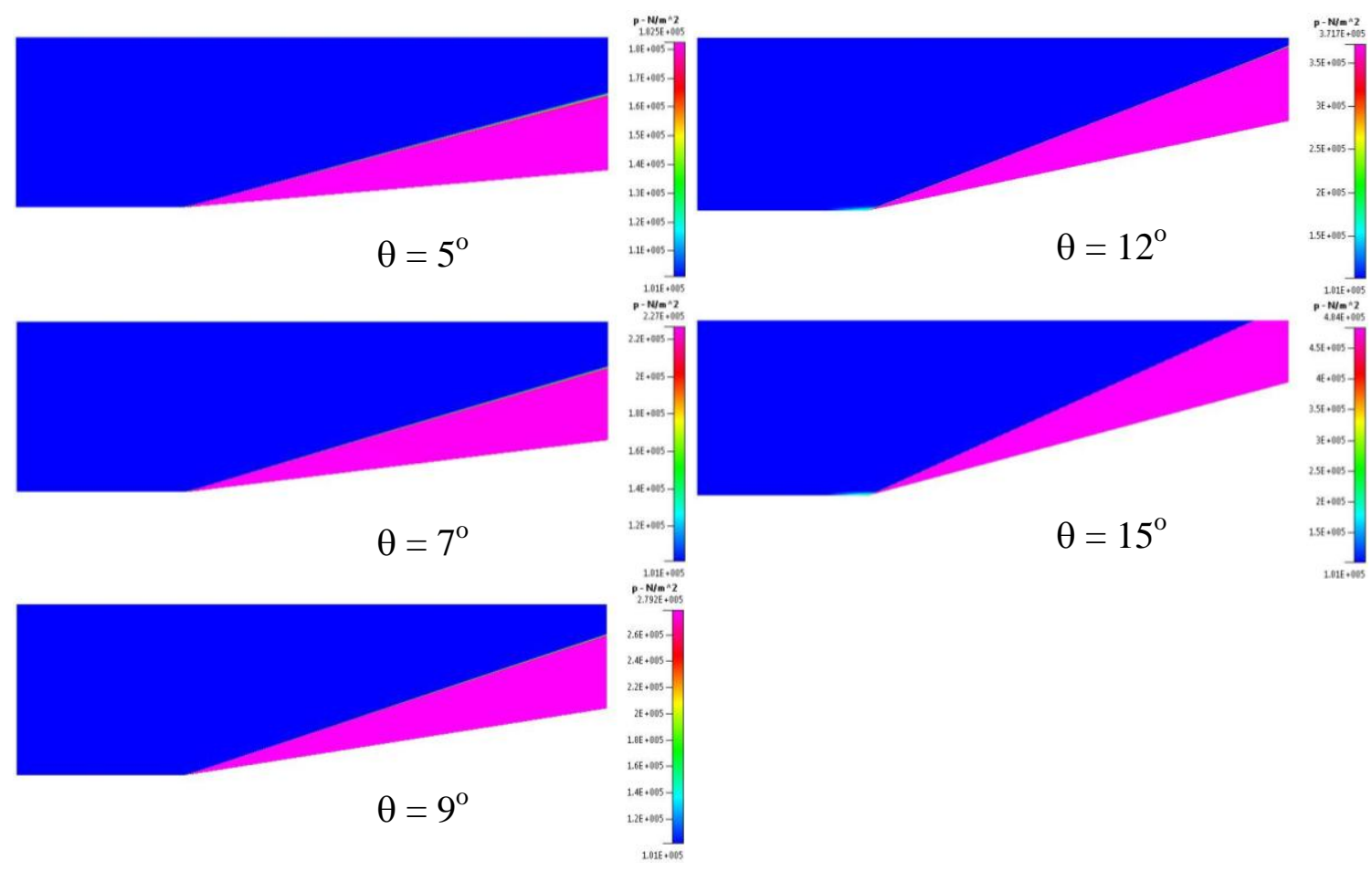

Figure 19 - Parametric study of turning angle of compression corners for pressure

Figure 19 shows how the pressure is affected as the turning angle increases. With a higher turning angle, the strength of the shock is greater, and the pressure after the shock is also greater. Increasing the turning angle increases the pressure after the shock. 

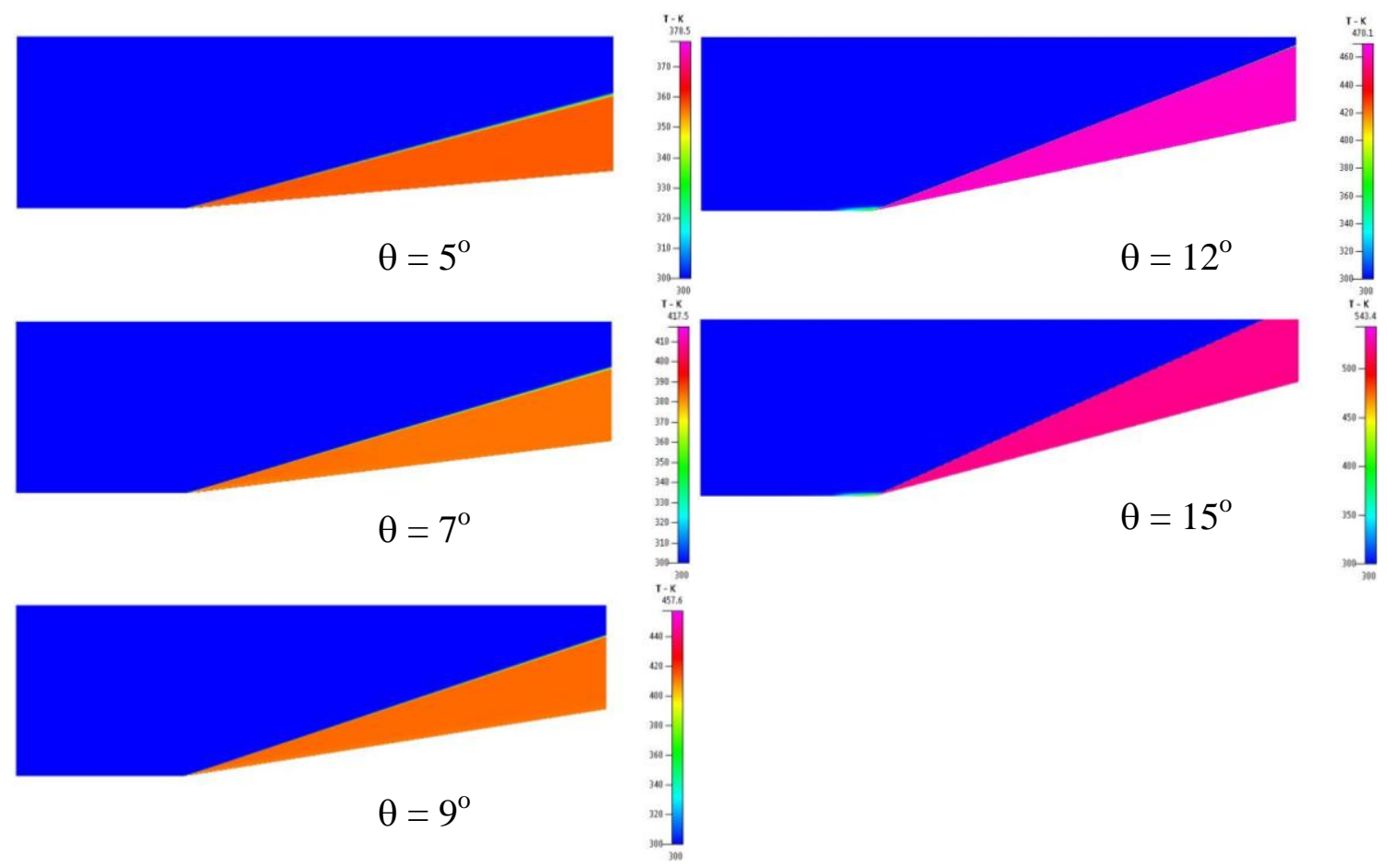

Figure 20 - Parametric study of turning angle of compression corners for temperature

Figure 20 shows how the temperature changes as the turning angle increases.

Similar to the pressure, the temperature increases as the turning angle increases.

For the same Mach number, the turning angle is varied from $5^{\circ}$ to $15^{\circ}$ to study how the shock is affected. Based on Figure 18, Figure 19, and Figure 20, the wave angle increases as the turning angle increases. Furthermore, the Mach number is decreased even further with a higher turning angle. The pressure and temperature after the shock are also increased. 


\subsubsection{Expansion Corners}

Similar to the compression corners, the parametric studies of Mach number and turning angle are performed to analyze the expansion corners. The results have the same format as the compression corners.

\subsubsection{Mach Number}

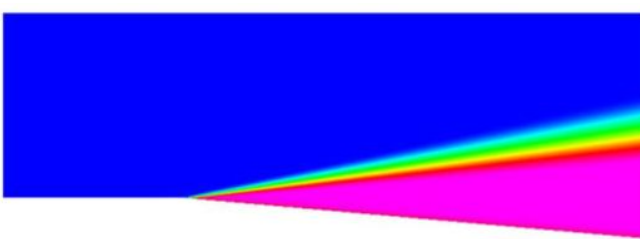

$\mathrm{M}=5$

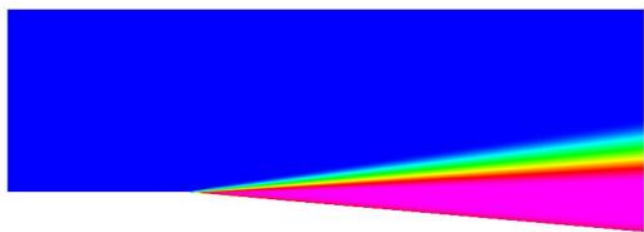

$\mathrm{M}=7$

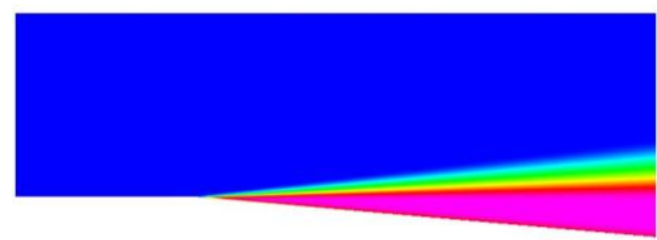

$\mathrm{M}=9$
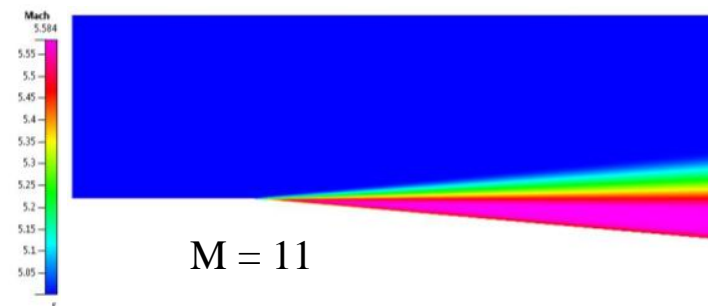

$$
\mathrm{M}=11
$$
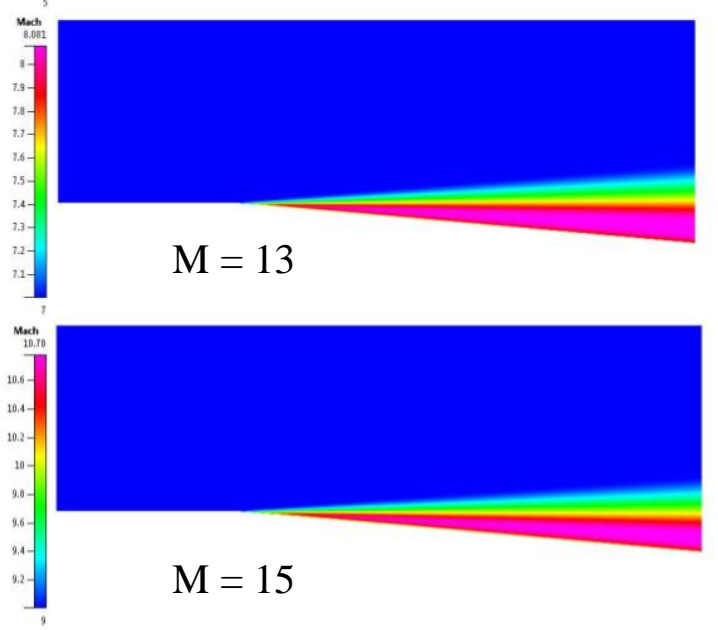

Figure 21 - Parametric study of Mach number of expansion corners for Mach number

Figure 21 shows how the Mach number after the shock is affected as the Mach number increases. From Figure 21, the Mach number after the shock increases as the Mach number increases. Furthermore, the wave angle decreases as the Mach number increases. 


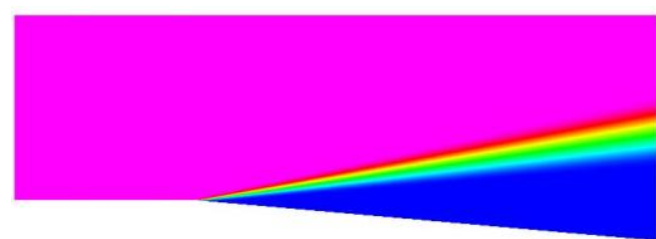

$\mathrm{M}=5$

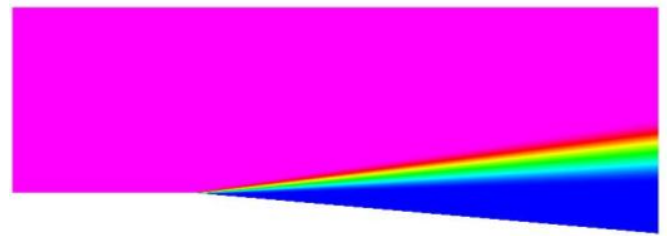

$\mathrm{M}=7$

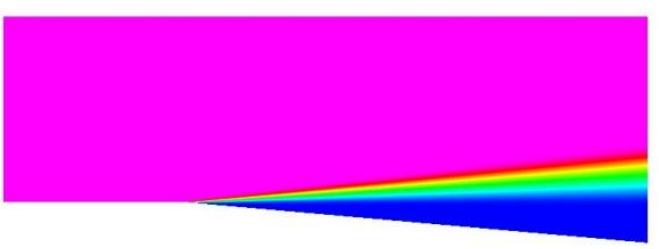

$M=9$

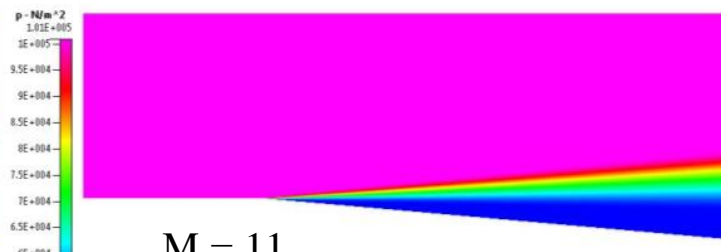

$$
\mathrm{M}=11
$$

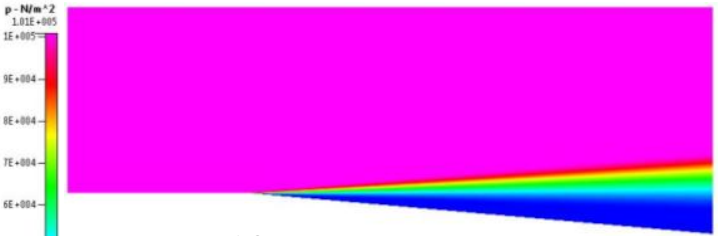

$$
M=13
$$

$$
\mathrm{M}=15
$$

Figure 22 - Parametric study of Mach number of expansion corners for pressure

Figure 22 shows how the pressure after the shock is affected as the Mach number increases. The strength of the shock increases as the Mach number increases. However, unlike the oblique shock, the expansion wave decreases the pressure after the shock. Higher strength of the shock magnifies the effects of the expansion wave. As a result, higher Mach number decreases the pressure after the shock. 


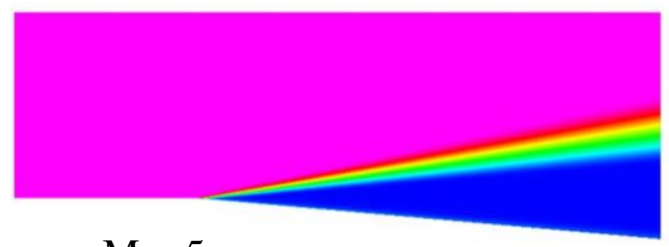

$M=5$

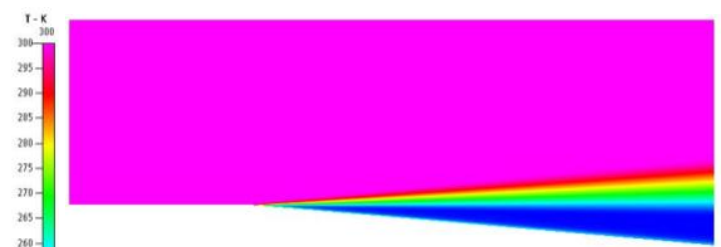

$\mathrm{M}=11$

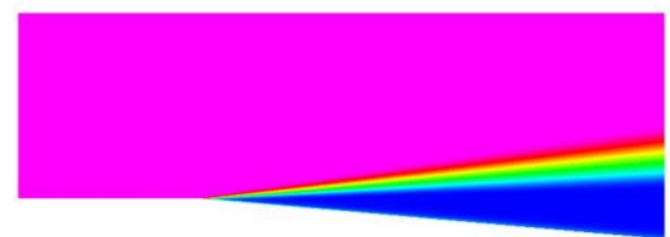

$M=7$

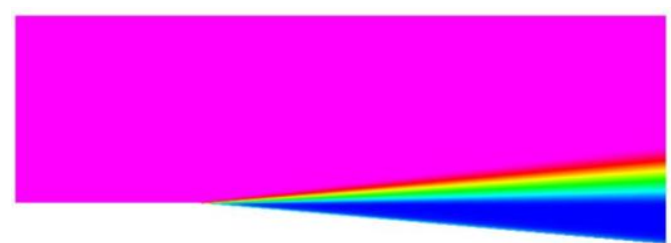

$M=9$

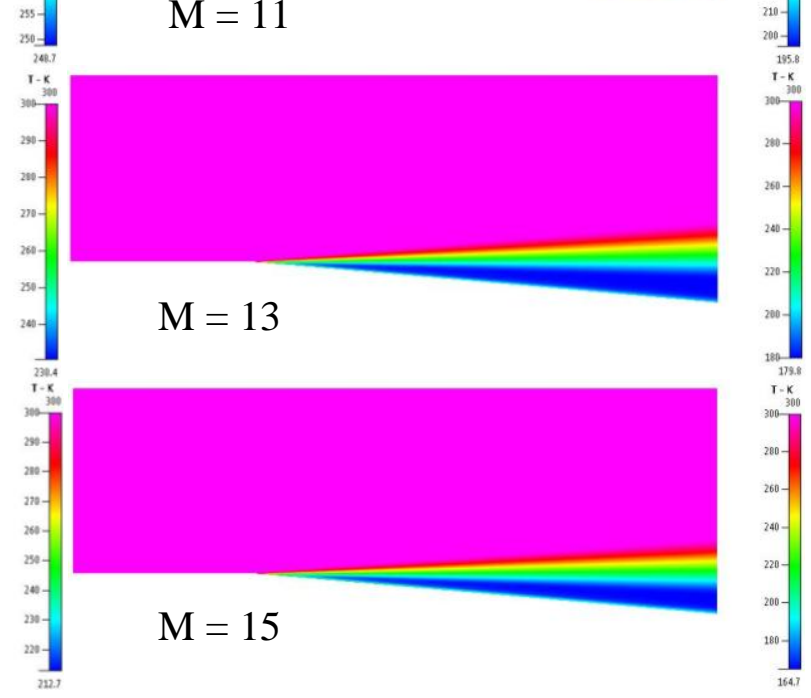

Figure 23 - Parametric study of Mach number of expansion corners for temperature

Figure 23 shows how the temperature after the shock is affected as the Mach number increases. Similar to the pressure for the expansion corner, the temperature after the shock decreases as the Mach number increases.

After viewing Figure 21, Figure 22, and Figure 23, it is evident that the wave angle is reduced with increased Mach numbers. Equally important, the pressure and temperature after the expansion wave are reduced with an increased Mach number. 


\subsubsection{Turning Angle}

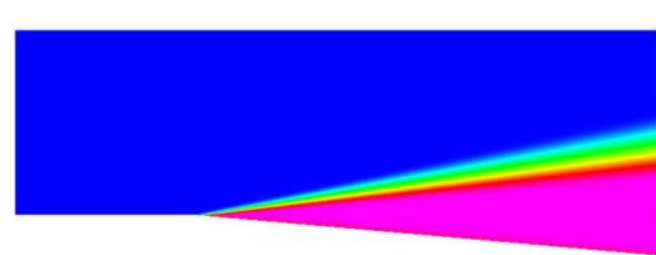

$$
\theta=5^{\circ}
$$

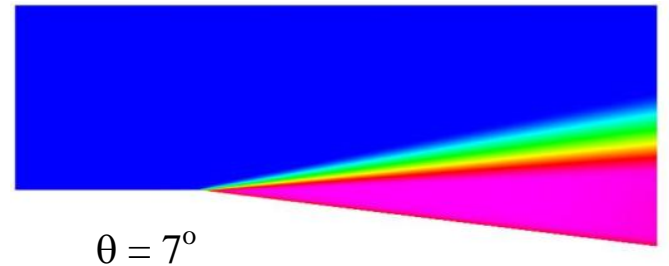

$\theta=7^{\circ}$

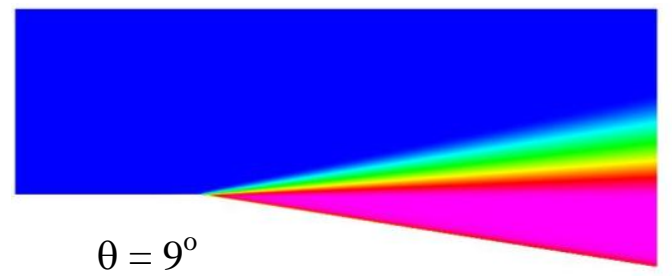

$\theta=9^{\circ}$
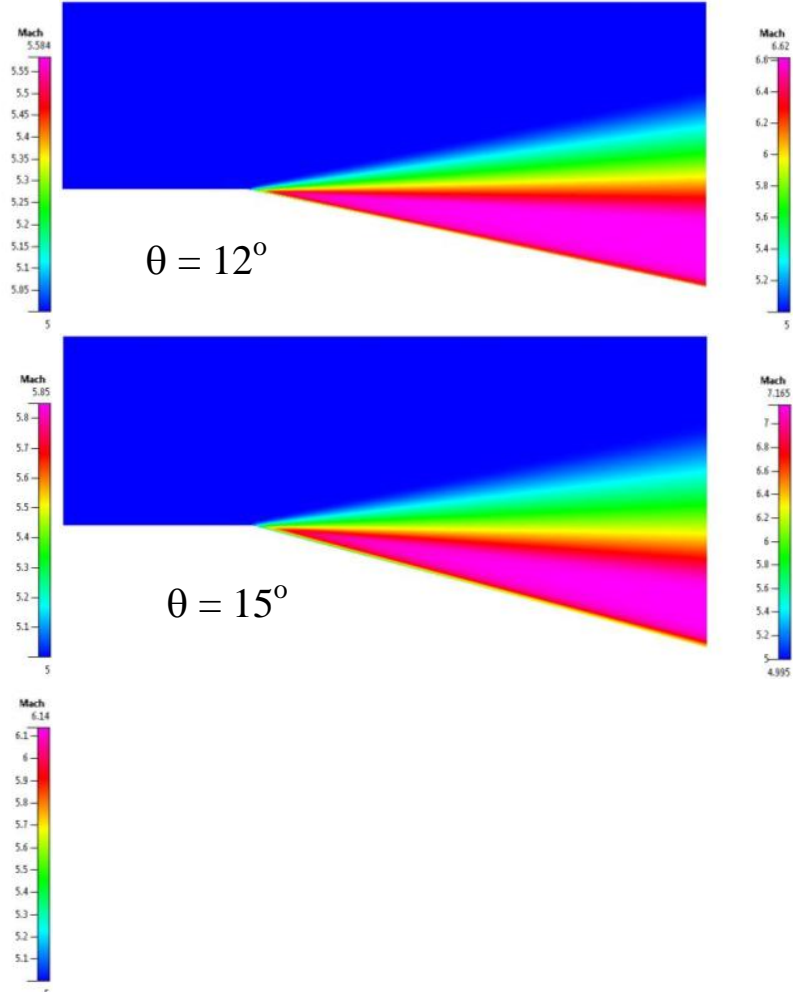

Figure 24 - Parametric study of turning angle of expansion corners for Mach number

Figure 24 shows how the Mach number after the shock is affected as the turning angle increases. The Mach number after the shock is found to be greater when the turning angle is higher. The wave angle, however, does not seem to be affected as the turning angle increases. 


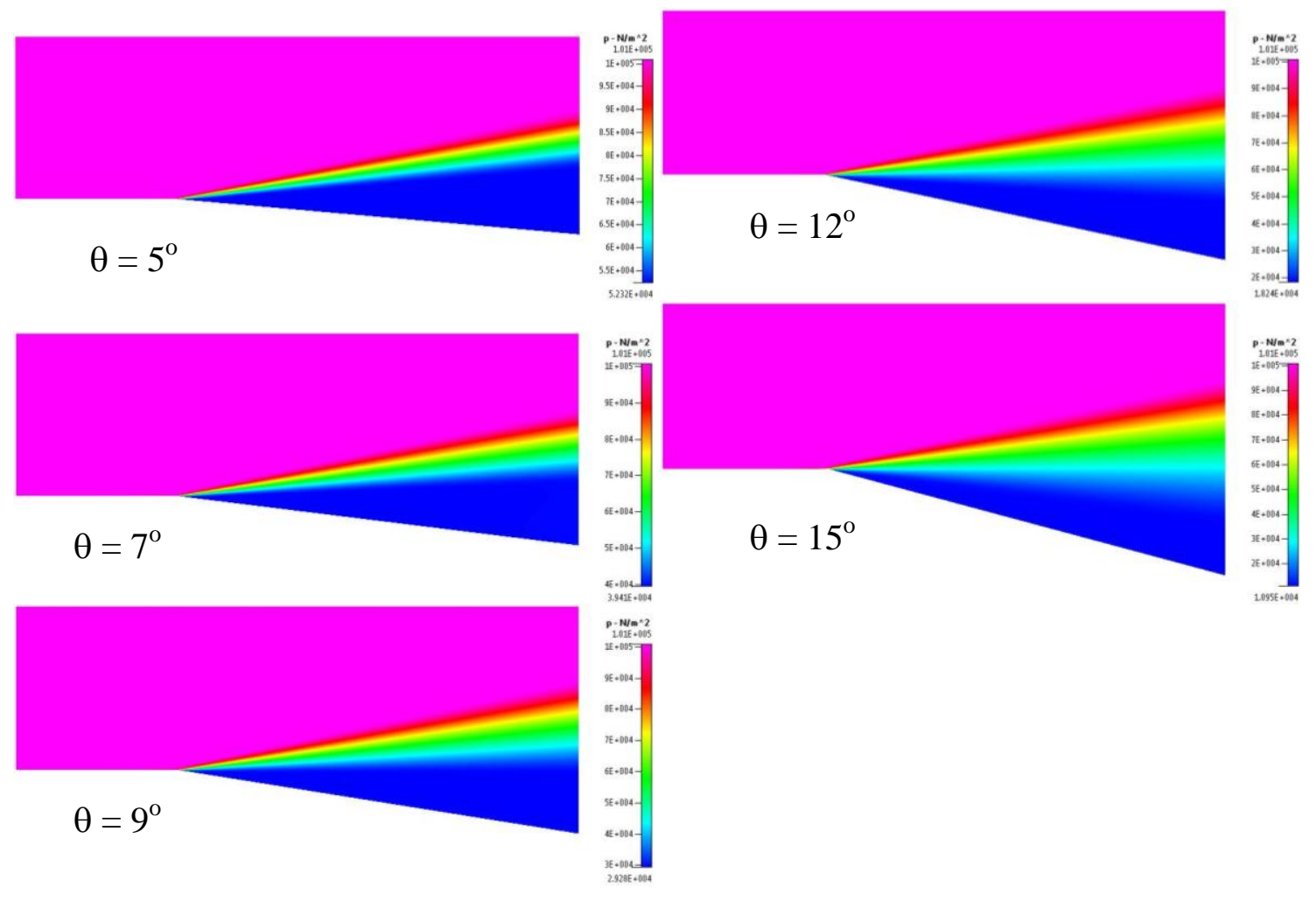

Figure 25 - Parametric study of turning angle of expansion corners for pressure

Figure 25 shows how the pressure after the shock is affected as the turning angle increases. Increasing the turning angle increases the strength of the shock. Consequently, the pressure after the shock decreases as the turning angle increases. 


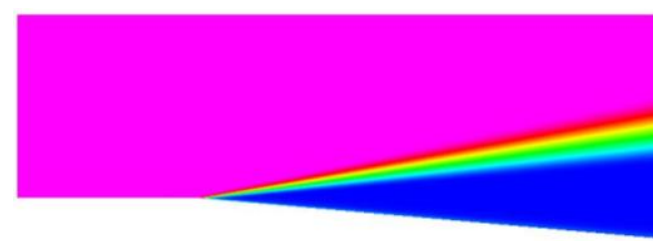

$\theta=5^{\mathrm{o}}$
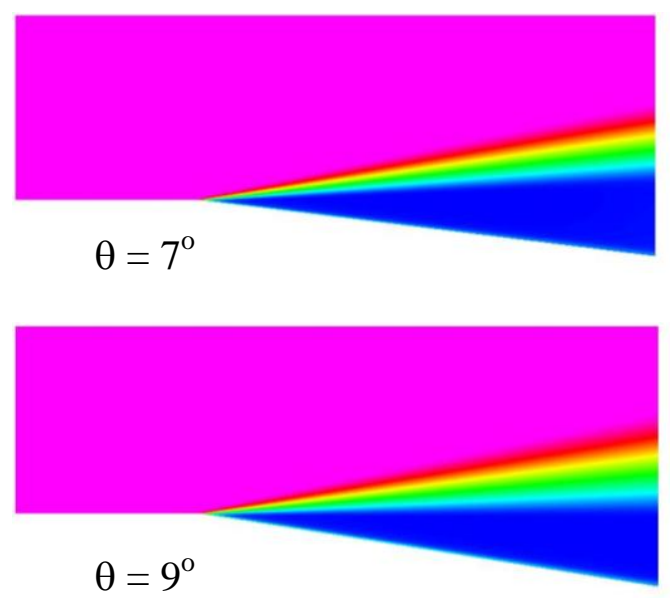

$\theta=9^{\circ}$
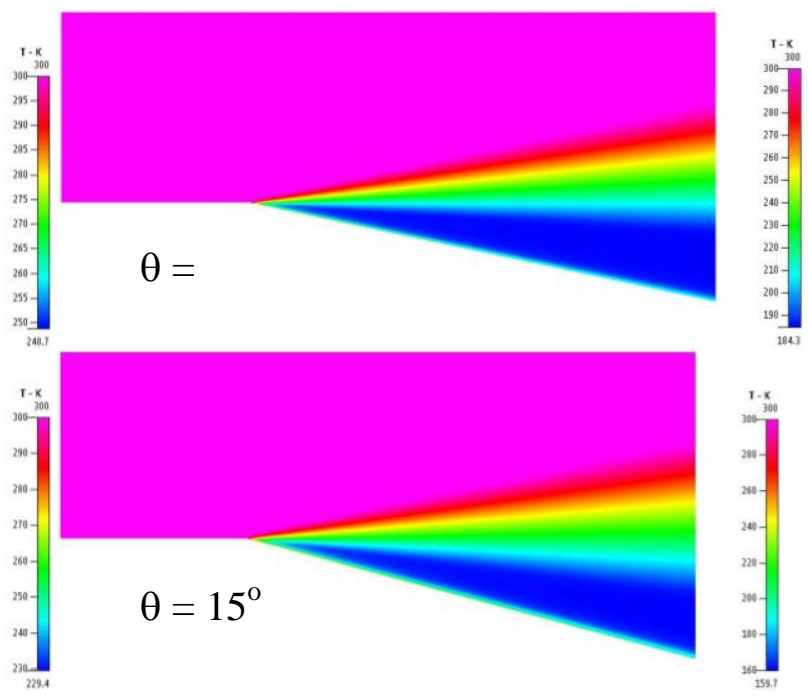

Figure 26 - Parametric study of turning angle of expansion corners for temperature

Figure 26 shows how the temperature after the shock is affected as the turning angle increases. Similar to the pressure, the temperature decreases as the turning angle increases.

Based on Figure 24, Figure 25, and Figure 26, increasing the turning angle helps to further accelerate the flow. As a result, the Mach number is increased with a higher turning angle. Furthermore, the pressure and temperature are reduced with a higher turning angle. 


\subsection{Discussion}

The investigation is performed mostly by using the commercial CFD software. CFD can perform flow simulation using the finite elements method. The accuracy of the simulation depends on the number of grid points. Because adding more grid points increases the simulation time, it is wise to place the grid points strategically. Fewer grid points are needed for the area where the flow is uniform, and more grid points are needed for the area where the changes take place. For the oblique shocks, the shocks are very thin, and thus should be represented as thin lines. However, the primarily results show that the gradient is thick. The discrepancy may be due to the numerical error. The results can be improved by adding more grid points to the area where the shock occurs. 


\section{Viscous Flow}

It is simple to solve for the inviscid cases; however, a real-life application is not that simple, and viscosity is always involved. To make the simulations more practical, the flows are now added with turbulence. A turbulent flow is chaotic in nature and very complicated. The flows are now considered viscous. The boundary layers are formed, and flow separation may occur because of the adverse pressure gradient. Due to viscosity, the flow is no longer uniform, the boundary layer is formed near the surface, and heat transfer occurs within the boundary layer. Because of the presence of the boundary layer, the flow is turned upward slightly. The displacement of the boundary layer is similar to a compression corner. The flow undergoes an oblique shock caused by the boundary layer and undergoes another shock caused by the compression or expansion corner. In regards to the viscous hypersonic flow, the flow undergoes two shocks, known as shock-shock interaction. The beauty of shock-shock interaction is that the first shock will affect the second shock. The properties of the flow are varied before the shock, so the properties of the flow after the shock are also varied to a degree. In the hypersonic flow cases, because the Mach number is very high, the boundary layer can be augmented. The most significant aspect of the hypersonic viscous flow is the heat transfer. The temperature within the boundary layer can build up to $11000 \mathrm{~K}$. Such a high temperature can result in significant damage to the spacecraft; therefore, the spacecraft is required to have thermal protection against such flows. Viscous flow is more practical and can reveal many details that inviscid flow cannot show. 
This thesis research was concentrated more on the compression corner rather than the expansion corner. The viscous expansion flow does not have much interaction with the boundary layer. Furthermore, turbulence is significantly reduced by the favorable pressure gradient. Figure 27 is the Mach number result for the viscous expansion flow. Aside from the formation of the boundary layer before the corner, there is not much difference from the inviscid flow. Viscosity does not significantly affect the flow. With regard to the compression corner, however, there is more physics involved with viscosity. The viscous simulation was focused on the compression corner. Further details are discussed below.
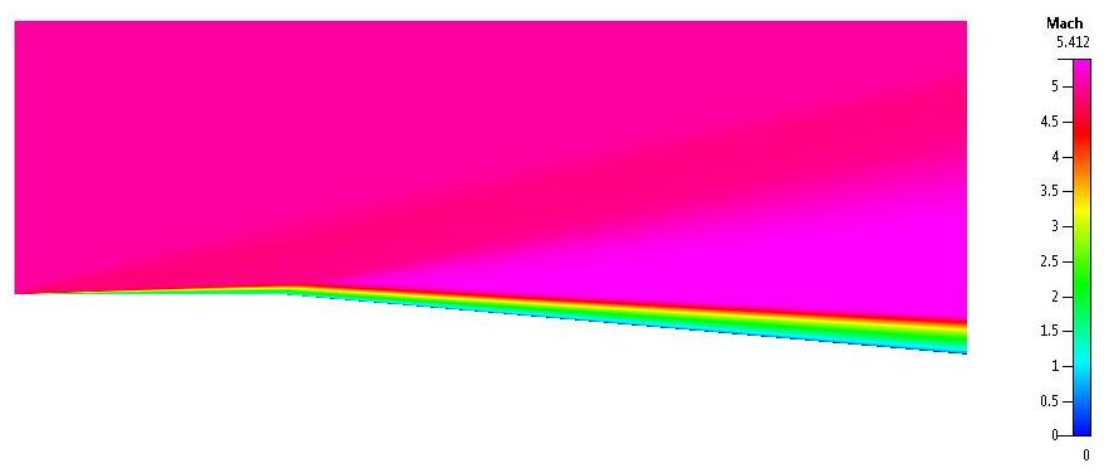

Figure 27 - Sample viscous expansion flow result

Since the theoretical calculations do not include viscosity, the goal of modeling the viscous flow is to find the correction factor for the data. The results for the inviscid flow, laminar flow, and turbulent flow are compared side-by-side to calculate the difference. The difference may be the correction factor needed to correct the flow. Table 2 contains the data for inviscid and viscous flows along with the percentage difference. Table 2 is for Mach 5 with various turning angles. The values of the properties are taken after the shock and above the boundary layer. The wave angle is calculated by taking the 
tangent of the shock location with respect to the pre-determined vertical distance. From

Table 2, the Mach number is different from $0 \%$ to $4 \%$, the pressure is different from $6 \%$

to $21 \%$, the temperature is different from $0 \%$ to $6 \%$, and the wave angle is increased from

$0 \%$ to $14 \%$.

Table 2 - After-shock data for different turning angles

\begin{tabular}{|c|c|c|c|c|c|c|}
\hline$\theta$ & Mach \# & Inviscid & Laminar & Turbulent & Laminar \% $\Delta$ & Turbulent \% $\Delta$ \\
\hline \multirow[t]{6}{*}{5} & 5 & & & & & \\
\hline & Shock Location (m) & 1.8 & 1.7 & 1.6 & & \\
\hline & Mach & 4.5 & 4.45 & 4.35 & $1.11 \%$ & $3.33 \%$ \\
\hline & Pressure $(\mathrm{kPa})$ & 182 & 193 & 220 & $6.04 \%$ & $20.88 \%$ \\
\hline & Temperature $(\mathrm{K})$ & 357 & 362 & 375 & $1.40 \%$ & $5.04 \%$ \\
\hline & Wave Angle $\left({ }^{\circ}\right)$ & 15.52 & 16.39 & 17.35 & $5.57 \%$ & $11.79 \%$ \\
\hline \multirow[t]{6}{*}{7} & 5 & & & & & \\
\hline & Shock Location $(\mathrm{m})$ & 1.6 & 1.5 & 1.4 & & \\
\hline & Mach & 4.31 & 4.27 & 4.19 & $0.93 \%$ & $2.78 \%$ \\
\hline & Pressure $(\mathrm{kPa})$ & 226 & 241 & 263 & $6.64 \%$ & $16.37 \%$ \\
\hline & Temperature $(\mathrm{K})$ & 384 & 387 & 398 & $0.78 \%$ & $3.65 \%$ \\
\hline & Wave Angle $\left({ }^{\circ}\right)$ & 17.35 & 18.43 & 19.65 & $6.23 \%$ & $13.25 \%$ \\
\hline \multirow[t]{6}{*}{9} & 5 & & & & & \\
\hline & Shock Location $(\mathrm{m})$ & 1.4 & 1.4 & 1.3 & & \\
\hline & Mach & 4.1 & 4.09 & 4 & $0.24 \%$ & $2.44 \%$ \\
\hline & Pressure $(\mathrm{kPa})$ & 278 & 295 & 322 & $6.12 \%$ & $15.83 \%$ \\
\hline & Temperature (K) & 413 & 414 & 428 & $0.24 \%$ & $3.63 \%$ \\
\hline & Wave Angle $\left({ }^{\circ}\right)$ & 19.65 & 19.65 & 21.04 & $0.00 \%$ & $7.04 \%$ \\
\hline \multirow[t]{6}{*}{12} & 5 & & & & & \\
\hline & Shock Location (m) & 2.5 & 2.4 & 2.3 & & \\
\hline & Mach & 3.8 & 3.86 & 3.82 & $1.58 \%$ & $0.53 \%$ \\
\hline & Pressure $(\mathrm{kPa})$ & 370 & 397 & 412 & $7.30 \%$ & $11.35 \%$ \\
\hline & Temperature $(\mathrm{K})$ & 462 & 452 & 461 & $2.16 \%$ & $0.22 \%$ \\
\hline & Wave Angle $\left({ }^{\circ}\right)$ & 21.80 & 22.62 & 23.50 & $3.75 \%$ & $7.78 \%$ \\
\hline \multirow[t]{6}{*}{15} & 5 & & & & & \\
\hline & Shock Location (m) & 2.2 & 2.15 & 2.1 & & \\
\hline & Mach & 3.5 & 3.59 & 3.56 & $2.57 \%$ & $1.71 \%$ \\
\hline & Pressure $(\mathrm{kPa})$ & 483 & 517 & 546 & $7.04 \%$ & $13.04 \%$ \\
\hline & Temperature $(\mathrm{K})$ & 520 & 503 & 510 & $3.27 \%$ & $1.92 \%$ \\
\hline & Wave Angle $\left({ }^{\circ}\right)$ & 24.44 & 24.94 & 25.46 & $2.05 \%$ & $4.17 \%$ \\
\hline
\end{tabular}


The behavior of the percentage difference can be seen more clearly in Figure 28, in which the wave angles of the inviscid flow, laminar flow, and turbulent flow are compared, showing how the wave angle changes with respect to the turning angle. These types of flows are graphed together; the vertical distance between each type of flow shows the discrepancy caused by the boundary layer. Evident in Figure 28, the inviscid flow has the lowest wave angle, and the turbulent flow has the highest wave angle. Based on earlier parametric studies, higher Mach number has a lower wave angle. The inviscid flow has a lower wave angle because it is not slowed by the boundary layer. However, the laminar and turbulent flows are slowed by the boundary layer. The boundary layer of a turbulent flow develops more rapidly than a laminar flow, so the turbulent flow undergoes a stronger shock because of the thicker boundary layer. The turbulent flow has a lower Mach number than the laminar flow when reaching a corner. As a result, turbulent flow has the highest wave angle, laminar flow has an intermediate wave angle, and inviscid flow has the lowest wave angle.

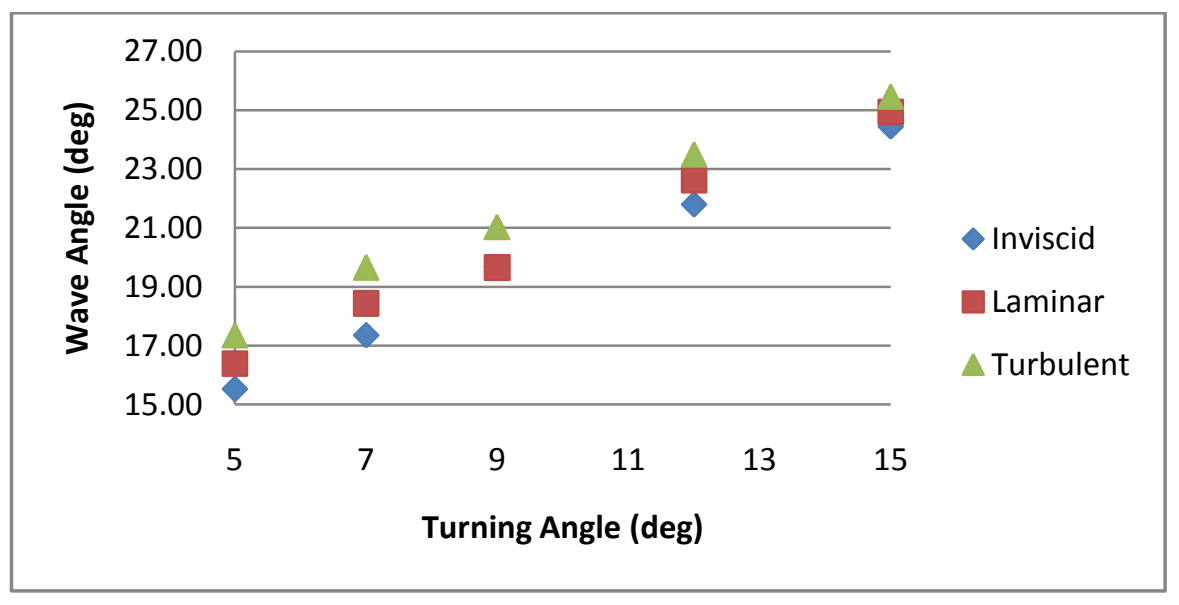

Figure 28 - Wave angle plot for different turning angles 
Figure 29 shows the percentage difference of the laminar and turbulent flow from the inviscid flow with respect to the turning angle. It is shown that the percentage difference in the pressure was the highest, followed by the percentage difference in the wave angle. The percentage difference in the Mach number and the temperature was very low. According to Figure 29, the percentage difference went down with an increasing turning angle. However, some data created a discrepancy. Some of the possible reasons for the discrepancy are due to the flow separation and the refinement level of the simulation. With high compression angles, the adverse pressure gradient can cause the flow to separate at the corner.

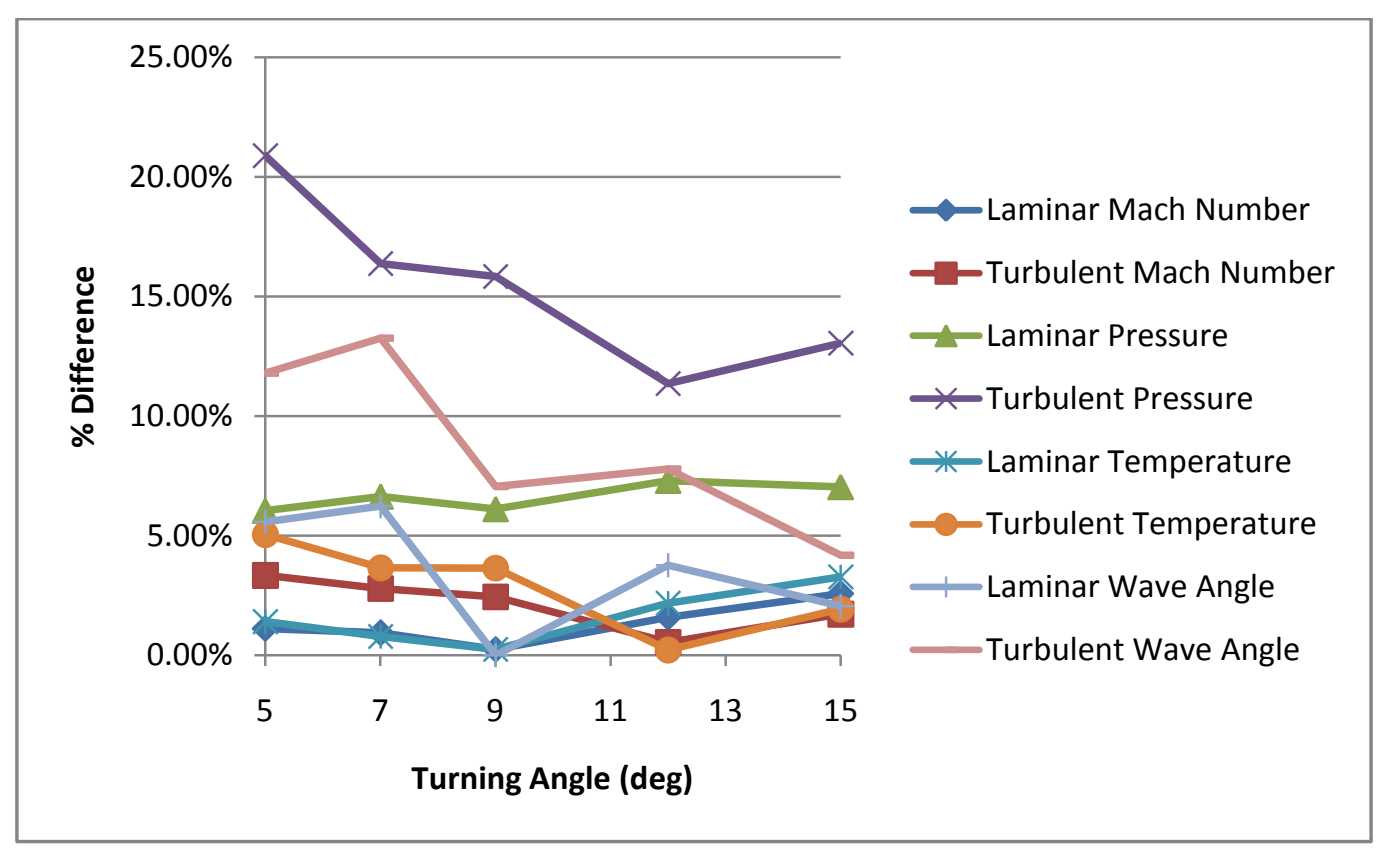

Figure 29 - After-shock percentage difference plot for different turning angles 
Table 3 - After-shock data for different Mach numbers

\begin{tabular}{|c|c|c|c|c|c|c|}
\hline$\theta$ & Mach & Inviscid & Laminar & Turbulent & Laminar $\% \Delta$ & Turbulent $\% \Delta$ \\
\hline \multirow[t]{6}{*}{5} & 5 & & & & & \\
\hline & Shock Location (m) & 1.8 & 1.7 & 1.6 & & \\
\hline & Mach & 4.5 & 4.45 & 4.35 & $1.11 \%$ & $3.33 \%$ \\
\hline & Pressure $(\mathrm{kPa})$ & 182 & 193 & 220 & $6.04 \%$ & $20.88 \%$ \\
\hline & Temperature (K) & 357 & 362 & 375 & $1.40 \%$ & $5.04 \%$ \\
\hline & Wave Angle $\left({ }^{\circ}\right)$ & 15.52 & 16.39 & 17.35 & $5.57 \%$ & $11.79 \%$ \\
\hline \multirow{6}{*}{5} & 7 & & & & & \\
\hline & Shock Location $(\mathrm{m})$ & 2.4 & 2.2 & 1.8 & & \\
\hline & Mach & 6.1 & 6.04 & 5.92 & $0.98 \%$ & $2.95 \%$ \\
\hline & Pressure $(\mathrm{kPa})$ & 226 & 245 & 276 & $8.41 \%$ & $22.12 \%$ \\
\hline & Temperature (K) & 386 & 390 & 404 & $1.04 \%$ & $4.66 \%$ \\
\hline & Wave Angle $\left({ }^{\circ}\right)$ & 11.77 & 12.80 & 15.52 & $8.80 \%$ & $31.91 \%$ \\
\hline \multirow[t]{6}{*}{5} & 9 & & & & & \\
\hline & Shock Location (m) & 2.7 & 2.5 & 2.1 & & \\
\hline & Mach & 7.59 & 7.49 & 7.35 & $1.32 \%$ & $3.16 \%$ \\
\hline & Pressure $(\mathrm{kPa})$ & 276 & 311 & 358 & $12.68 \%$ & $29.71 \%$ \\
\hline & Temperature (K) & 414 & 421 & 437 & $1.69 \%$ & $5.56 \%$ \\
\hline & Wave Angle $\left({ }^{\circ}\right)$ & 10.49 & 11.31 & 13.39 & $7.80 \%$ & $27.65 \%$ \\
\hline \multirow[t]{6}{*}{5} & 11 & & & & & \\
\hline & Shock Location (m) & 3 & 2.7 & 2.3 & & \\
\hline & Mach & 8.92 & 8.86 & 8.76 & $0.67 \%$ & $1.79 \%$ \\
\hline & Pressure $(\mathrm{kPa})$ & 336 & 384 & 430 & $14.29 \%$ & $27.98 \%$ \\
\hline & Temperature $(\mathrm{K})$ & 445 & 452 & 462 & $1.57 \%$ & $3.82 \%$ \\
\hline & Wave Angle $\left(^{\circ}\right)$ & 9.46 & 10.49 & 12.26 & $10.88 \%$ & $29.62 \%$ \\
\hline \multirow{6}{*}{5} & 13 & & & & & \\
\hline & Shock Location (m) & 3.3 & 2.8 & 2.4 & & \\
\hline & Mach & 10.2 & 10.14 & 10 & $0.59 \%$ & $1.96 \%$ \\
\hline & Pressure $(\mathrm{kPa})$ & 404 & 465 & 524 & $15.10 \%$ & $29.70 \%$ \\
\hline & Temperature $(\mathrm{K})$ & 480 & 484 & 496 & $0.83 \%$ & $3.33 \%$ \\
\hline & Wave Angle $\left({ }^{\circ}\right)$ & 8.62 & 10.12 & 11.77 & $17.51 \%$ & $36.59 \%$ \\
\hline \multirow[t]{6}{*}{5} & 15 & & & & & \\
\hline & Shock Location (m) & 3.5 & 2.7 & 2.5 & & \\
\hline & Mach & 11.3 & 10.99 & 11.2 & $2.74 \%$ & $0.88 \%$ \\
\hline & Pressure $(\mathrm{kPa})$ & 480 & 548 & 642 & $14.17 \%$ & $33.75 \%$ \\
\hline & Temperature $(\mathrm{K})$ & 520 & 547 & 530 & $5.19 \%$ & $1.92 \%$ \\
\hline & Wave Angle $\left({ }^{\circ}\right)$ & 8.13 & 10.49 & 11.31 & $29.04 \%$ & $39.11 \%$ \\
\hline
\end{tabular}

Similar to Table 2, Table 3 is the comparison of the inviscid flow, the laminar flow, and the turbulent flow with respect to the Mach number. The Mach number is 
different from $0 \%$ to $4 \%$, the pressure is different from $8 \%$ to $34 \%$, the temperature is different from $0 \%$ to $6 \%$, and the wave angle is increased from $5 \%$ to $40 \%$. Graphing the data in Table 3 produces Figure 30 and Figure 31.

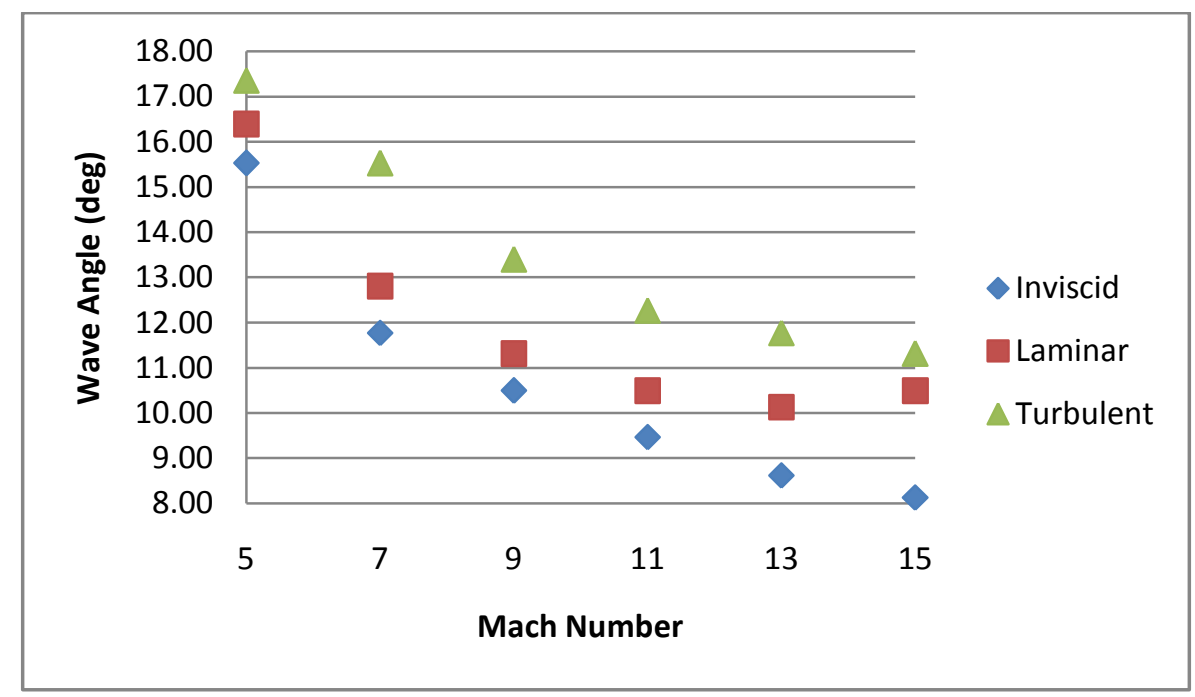

Figure 30- Wave angle plot for different Mach numbers

Figure 30 is a graph of the wave angles of the inviscid, laminar, and turbulent flows with respect to the Mach number. Similar to Figure 28, the inviscid flow had the lowest wave angle, and the turbulent flow had the highest wave angle. As the Mach number increases, the wave angle decreases. The boundary layer grew more rapidly as the Mach number increased. A thicker boundary layer caused the flow to turn more upward, causing a stronger shock. The Mach number was then reduced before the flow hit the corner. Similarly, the turbulent flow had a thicker boundary layer than the laminar flow, so the turbulent flow was affected more by the boundary layer. 


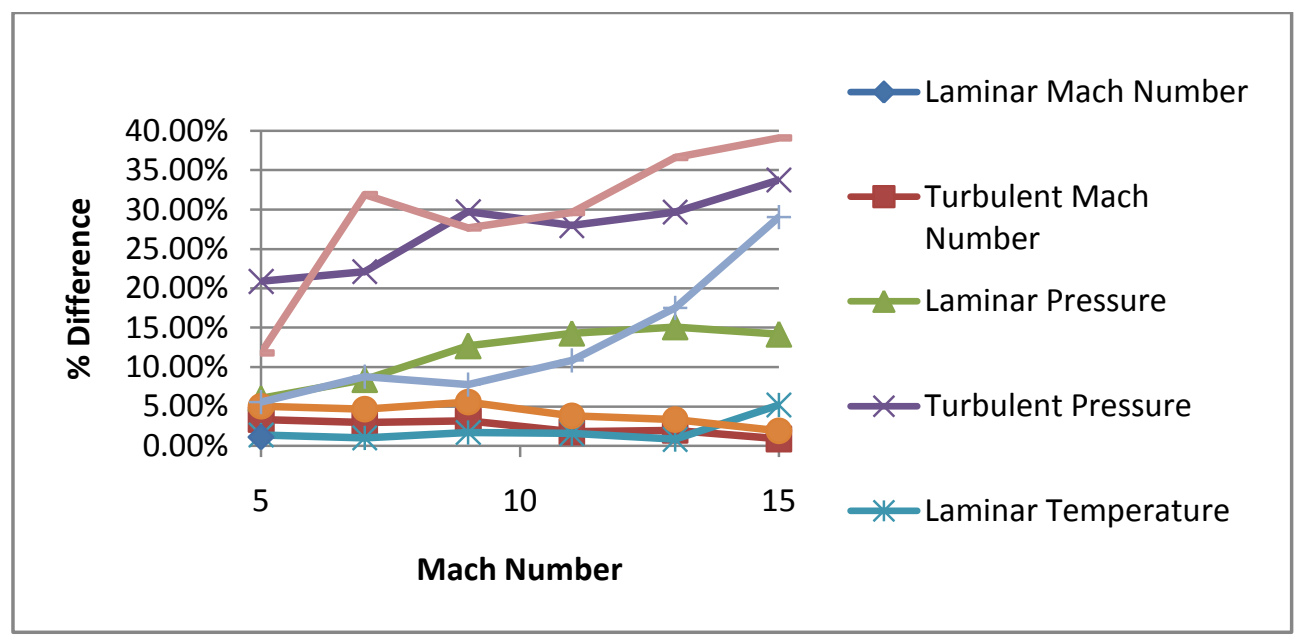

Figure 31 - After-shock percentage difference plot for different Mach numbers

Figure 31 shows the percentage difference between the laminar and turbulent flow with respect to Mach number. All the properties seem to be increasing until they reach a high Mach number. At a high Mach number, the flow undergoes "viscous interaction phenomena" where the shock layer is thin and the boundary layer is thick (Anderson, 2007). The shock layer becomes totally viscous, so there is no distinction between the shock layer and the boundary layer. Overall, the pressure and the wave angle have the highest percentage difference, and the temperature and Mach number have the smallest percentage difference.

The percentage difference in Table 2 and Table 3 are caused by the boundary layer. Before the flow reaches the corner, it undergoes an oblique shock caused by the boundary layer. The properties, such as the Mach number, pressure, and temperature, are changed by the shock. Consequently, the properties after the shock are also changed, causing the percentage difference in Table 2 and Table 3 . Theoretical calculations are 
done to validate the results. The calculations are the same as the inviscid flow except for the flow properties that are altered by the boundary layer.

For $\mathrm{M}=5$ and $\theta=5^{\circ}$ compression corner case, the initial properties are then changed to $\mathrm{M}=4.82, \mathrm{p}_{1}=120 \mathrm{kPa}$, and $\mathrm{T}_{1}=320 \mathrm{~K}$ because of the boundary layer. Calculating $\beta$ to be $15.5^{\circ}$ from Equation (3).

$$
\mathrm{M}_{\mathrm{n} 1}=\mathrm{M}_{1} \sin \beta=4.82 \sin \left(15.5^{\circ}\right)=1.29
$$

Calculating the normal shock relation for $\mathrm{M}=1.29$ with Equation (4), (5), and (6).

$$
\begin{aligned}
& \frac{p 2}{p 1}=1.775, \quad \frac{T 2}{T 1}=1.185, \quad \mathrm{M}_{\mathrm{n} 2}=0.7911 \\
& \mathrm{p}_{2}=\frac{p 2}{p 1} \mathrm{p}_{1}=1.775(120 \mathrm{kPa})=213 \mathrm{kPa} \\
& \mathrm{T}_{2}=\frac{T 2}{T 1} \mathrm{~T}_{1}=1.185(320 \mathrm{~K})=379 \mathrm{~K} \\
& \mathrm{M}_{2}=\frac{M n 2}{\sin ((b-\mathrm{q})}=\frac{0.7911}{\sin (15.5-5)}=4.34
\end{aligned}
$$

Compared to the computational values, 4.34 to 4.35 for Mach number, 213 to 220 $\mathrm{kPa}$ for pressure, and 379 to $375 \mathrm{~K}$ for temperature, the values are close. The calculations show that the method to solve the viscous flow is the same as the inviscid flow. The difference for the viscous flow is that the properties are changed by the boundary layer. Theoretical equations for the oblique shock do not take the boundary layer into consideration. The results can tell how much the viscous flow is different from the inviscid flow. The percentage difference can be used as the correction factor to correct the offset. 
The data in Table 2 and Table 3 show the extent in which the properties of the flow are affected by viscosity. The data are taken after the shock and above the boundary layer. There are differences from the inviscid flow because the flow undergoes a shock before it reaches the corner. The properties of the flow before the shock are changed, so the properties after the shock are also changed. Table 4 and Table 5 contain the data of the flow immediately before the shock. The differences indicate the degree in which the boundary layer affects the flow.

Table 4 - Before-shock data for different turning angles

\begin{tabular}{|c|c|c|c|c|c|c|}
\hline$\theta$ & Mach & Inviscid & Laminar & Turbulent & Laminar \% $\Delta$ & Turbulent $\% \Delta$ \\
\hline \multirow[t]{4}{*}{5} & 5 & & & & & \\
\hline & Mach & 5 & 4.81 & 4.82 & $3.80 \%$ & $3.60 \%$ \\
\hline & Pressure $(\mathrm{kPa})$ & 101 & 125 & 124 & $23.76 \%$ & $22.77 \%$ \\
\hline & Temperature (K) & 300 & 320 & 320 & $6.67 \%$ & $6.67 \%$ \\
\hline \multirow[t]{4}{*}{7} & 5 & & & & & \\
\hline & Mach & 5 & 4.81 & 4.82 & $3.80 \%$ & $3.60 \%$ \\
\hline & Pressure $(\mathrm{kPa})$ & 101 & 125 & 125 & $23.76 \%$ & $23.76 \%$ \\
\hline & Temperature $(\mathrm{K})$ & 300 & 320 & 320 & $6.67 \%$ & $6.67 \%$ \\
\hline \multirow[t]{4}{*}{9} & 5 & & & & & \\
\hline & Mach & 5 & 4.82 & 4.85 & $3.60 \%$ & $3.00 \%$ \\
\hline & Pressure $(\mathrm{kPa})$ & 101 & 125 & 120 & $23.76 \%$ & $18.81 \%$ \\
\hline & Temperature (K) & 300 & 320 & 315 & $6.67 \%$ & $5.00 \%$ \\
\hline \multirow[t]{4}{*}{12} & 5 & & & & & \\
\hline & Mach & 5 & 4.73 & 4.72 & $5.40 \%$ & $5.60 \%$ \\
\hline & Pressure $(\mathrm{kPa})$ & 101 & 140 & 141 & $38.61 \%$ & $39.60 \%$ \\
\hline & Temperature $(\mathrm{K})$ & 300 & 330 & 330 & $10.00 \%$ & $10.00 \%$ \\
\hline \multirow[t]{4}{*}{15} & 5 & & & & & \\
\hline & Mach & 5 & 4.7 & 4.68 & $6.00 \%$ & $6.40 \%$ \\
\hline & Pressure $(\mathrm{kPa})$ & 101 & 144 & 146 & $42.57 \%$ & $44.55 \%$ \\
\hline & Temperature $(\mathrm{K})$ & 300 & 332 & 334 & $10.67 \%$ & $11.33 \%$ \\
\hline
\end{tabular}


Figure 32 is the graph of the percentage difference. As stated earlier, the pressure has the highest percentage difference, followed by the temperature and then the Mach number. Moreover, the percentage difference seems to be constant for low turning angles and appears to rise at high turning angles. This behavior is expected because the only factor affecting the flow is the boundary layer. The growth of the boundary layer depends on the distance traveled and the Reynolds number. The distance traveled is kept constant, and the Reynolds number depends on the velocity, which is related to the Mach number, and is also kept constant. The boundary layer, then, is also kept constant, so the angle of the displacement and the strength of the shock are also constant.

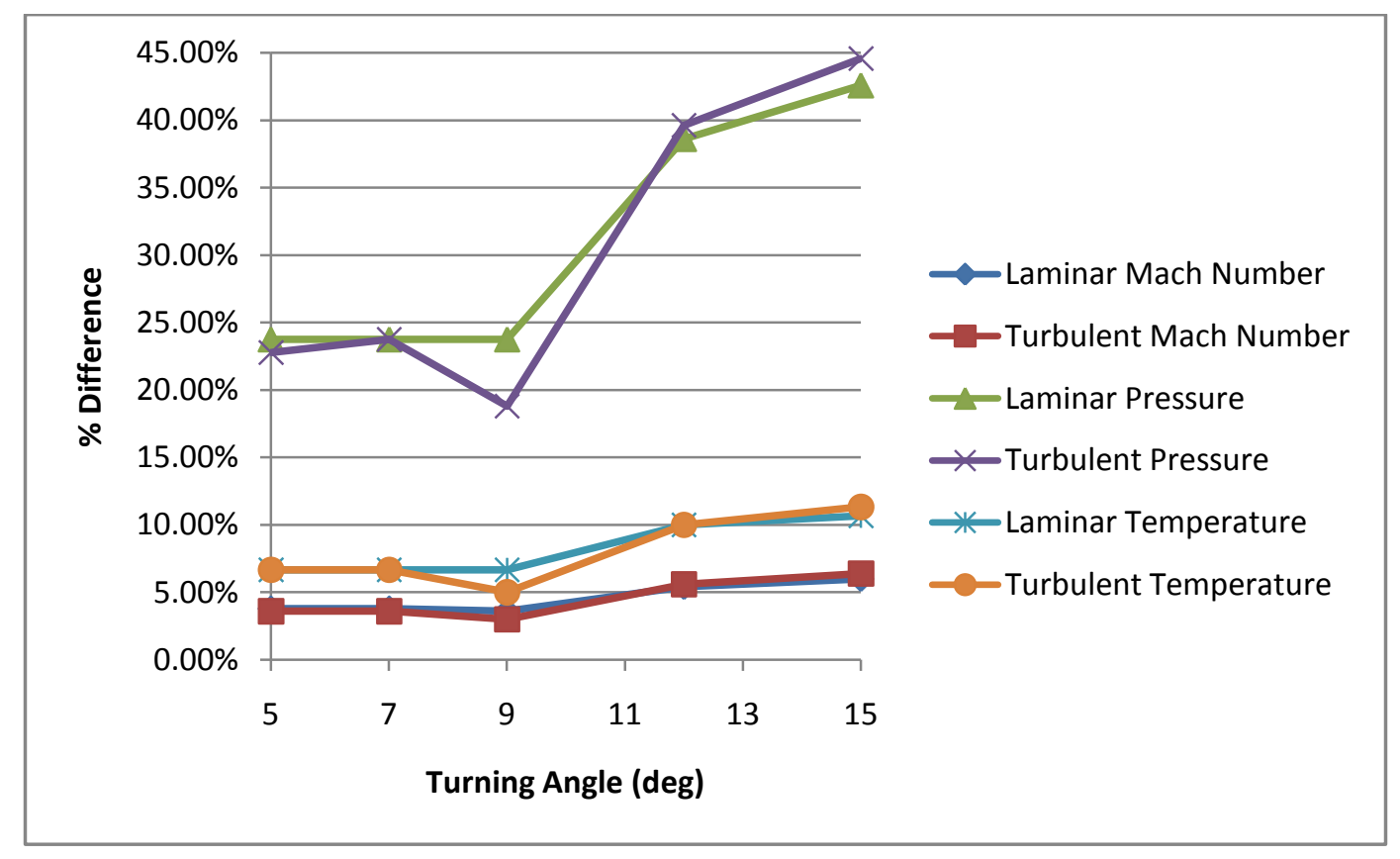

Figure 32 - Before-shock percentage difference plot for different turning angles 
Table 5 - Before-shock data for different Mach numbers

\begin{tabular}{|c|c|c|c|c|c|c|}
\hline$\theta$ & Mach & Inviscid & Laminar & Turbulent & Laminar \% $\Delta$ & Turbulent $\% \Delta$ \\
\hline \multirow[t]{4}{*}{5} & 5 & & & & & \\
\hline & Mach & 5 & 4.81 & 4.82 & $3.80 \%$ & $3.60 \%$ \\
\hline & Pressure $(\mathrm{kPa})$ & 101 & 125 & 124 & $23.76 \%$ & $22.77 \%$ \\
\hline & Temperature $(\mathrm{K})$ & 300 & 320 & 320 & $6.67 \%$ & $6.67 \%$ \\
\hline \multirow[t]{4}{*}{5} & 7 & & & & & \\
\hline & Mach & 7 & 6.72 & 6.59 & $4.00 \%$ & $5.86 \%$ \\
\hline & Pressure $(\mathrm{kPa})$ & 101 & 129 & 145 & $27.72 \%$ & $43.56 \%$ \\
\hline & Temperature (K) & 300 & 323 & 334 & $7.67 \%$ & $11.33 \%$ \\
\hline \multirow[t]{4}{*}{5} & 9 & & & & & \\
\hline & Mach & 9 & 8.43 & 8.36 & $6.33 \%$ & $7.11 \%$ \\
\hline & Pressure $(\mathrm{kPa})$ & 101 & 150 & 162 & $48.51 \%$ & $60.40 \%$ \\
\hline & Temperature (K) & 300 & 339 & 344 & $13.00 \%$ & $14.67 \%$ \\
\hline \multirow[t]{4}{*}{5} & 11 & & & & & \\
\hline & Mach & 11 & 10.09 & 9.72 & $8.27 \%$ & $11.64 \%$ \\
\hline & Pressure $(\mathrm{kPa})$ & 101 & 172 & 224 & $70.30 \%$ & $121.78 \%$ \\
\hline & Temperature (K) & 300 & 354 & 380 & $18.00 \%$ & $26.67 \%$ \\
\hline \multirow[t]{4}{*}{5} & 13 & & & & & \\
\hline & Mach & 13 & 11.64 & 11.39 & $10.46 \%$ & $12.38 \%$ \\
\hline & Pressure $(\mathrm{kPa})$ & 101 & 200 & 237 & $98.02 \%$ & $134.65 \%$ \\
\hline & Temperature (K) & 300 & 372 & 387 & $24.00 \%$ & $29.00 \%$ \\
\hline \multirow[t]{4}{*}{5} & 15 & & & & & \\
\hline & Mach & 15 & 12.69 & 12.29 & $15.40 \%$ & $18.07 \%$ \\
\hline & Pressure $(\mathrm{kPa})$ & 101 & 258 & 350 & $155.45 \%$ & $246.53 \%$ \\
\hline & Temperature $(\mathrm{K})$ & 300 & 415 & 443 & $38.33 \%$ & $47.67 \%$ \\
\hline
\end{tabular}

The percentage difference for all the properties of the flow is plotted in Figure 33. As usual, the pressure has the highest percentage difference, followed by the temperature and then the Mach number. The percentage difference increases as the Mach number 
increases, due to the growth of the boundary layer. As the Mach number increases, the Reynolds number also increases, and the boundary layer also becomes thicker. The thickened boundary layer turns the flow more upward, thus, creating a stronger shock. The pressure and temperature after the shock are increased, and another shock would continue to increase these two properties further.

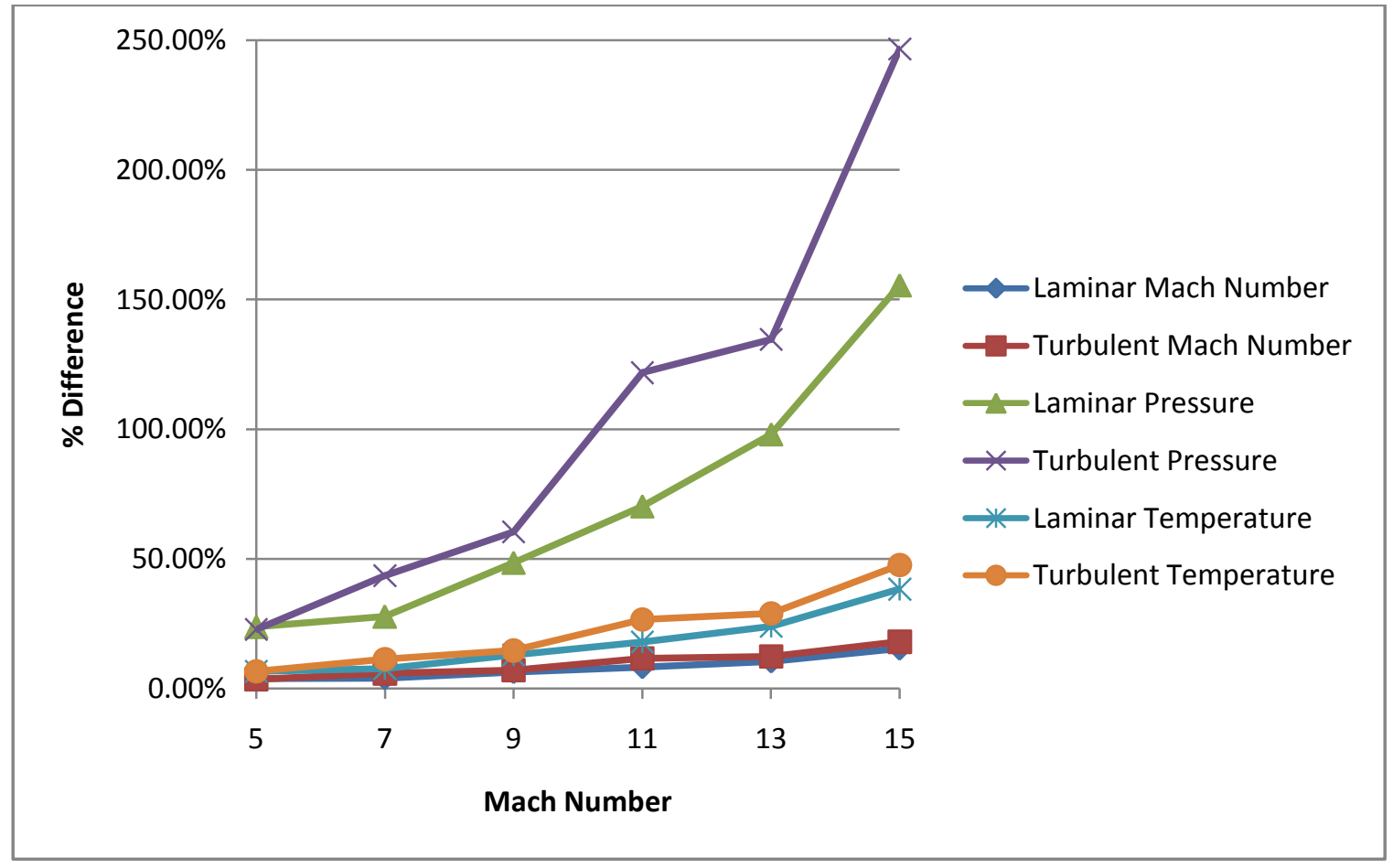

Figure 33 - Before-shock percentage difference plot for different Mach numbers 
From Figure 34, the range of the Mach number of the viscous flow is wider than the inviscid flow because of the boundary layer. The velocity at the wall is zero and gradually increases until it reaches the freestream velocity. The area where the velocity changes from zero to the freestream velocity is the boundary layer. The boundary layer is indicated by the color gradient immediately above the wall, which is the area where heat transfer occurs. Further analysis of the viscous flow can be found in Figure 35.
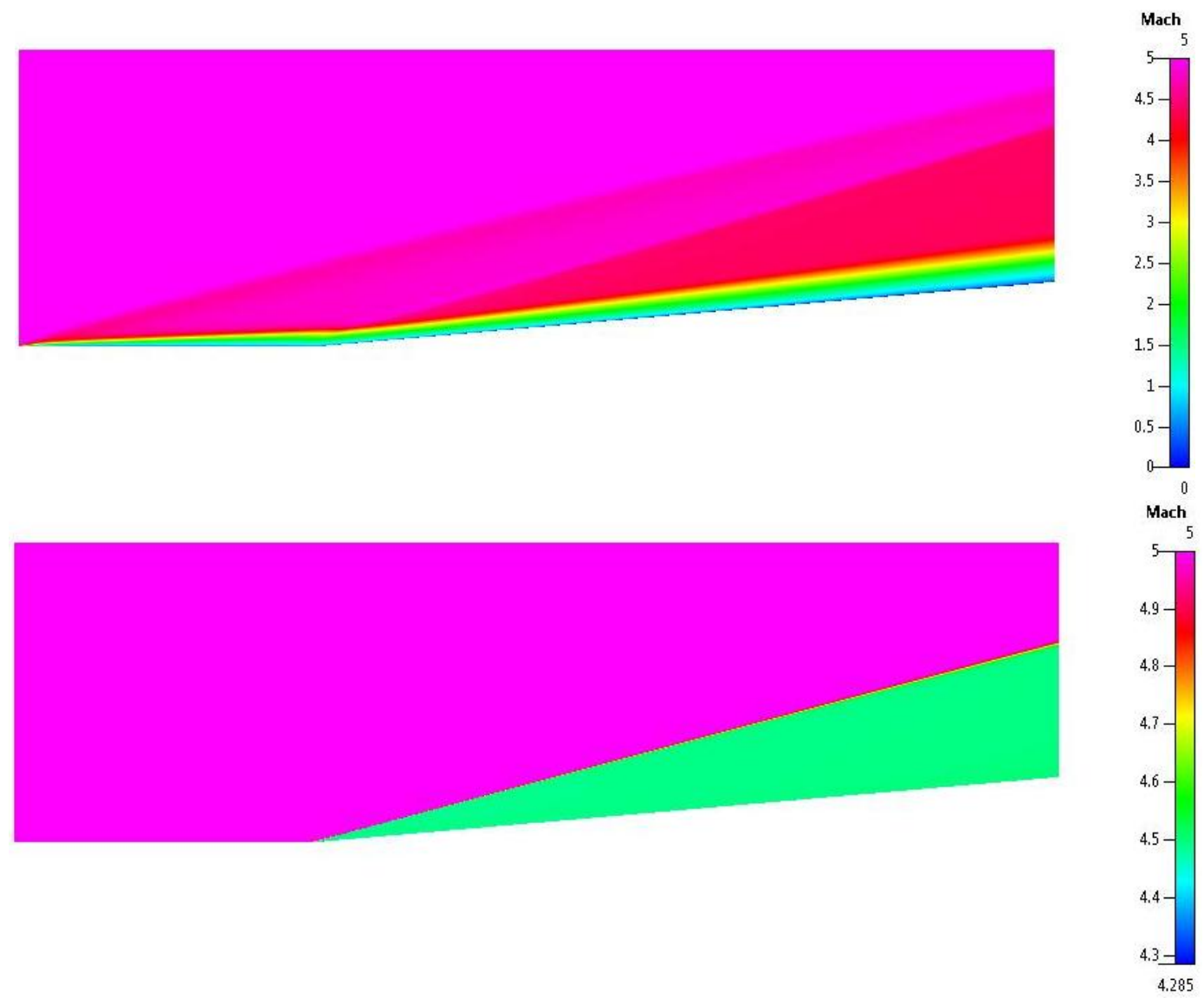

Figure 34 - Viscous (top) and inviscid (bottom) flow comparison 


\subsection{Flow Separation}

Figure 35 is the magnified viscous flow result with the velocity profile added. The velocity profile is measured vertically at the corner. Because ESI does not have the capability to plot the velocity normal to an angled wall, plotting the freestream velocity is the best alternative to show the separated flow. From the velocity profile, there is a slight area where the velocity is negative at the bottom. The negative velocity indicates the flow is going in the opposite direction. The reversed flow indicates that the flow has separated from the wall and falls back on the slope.
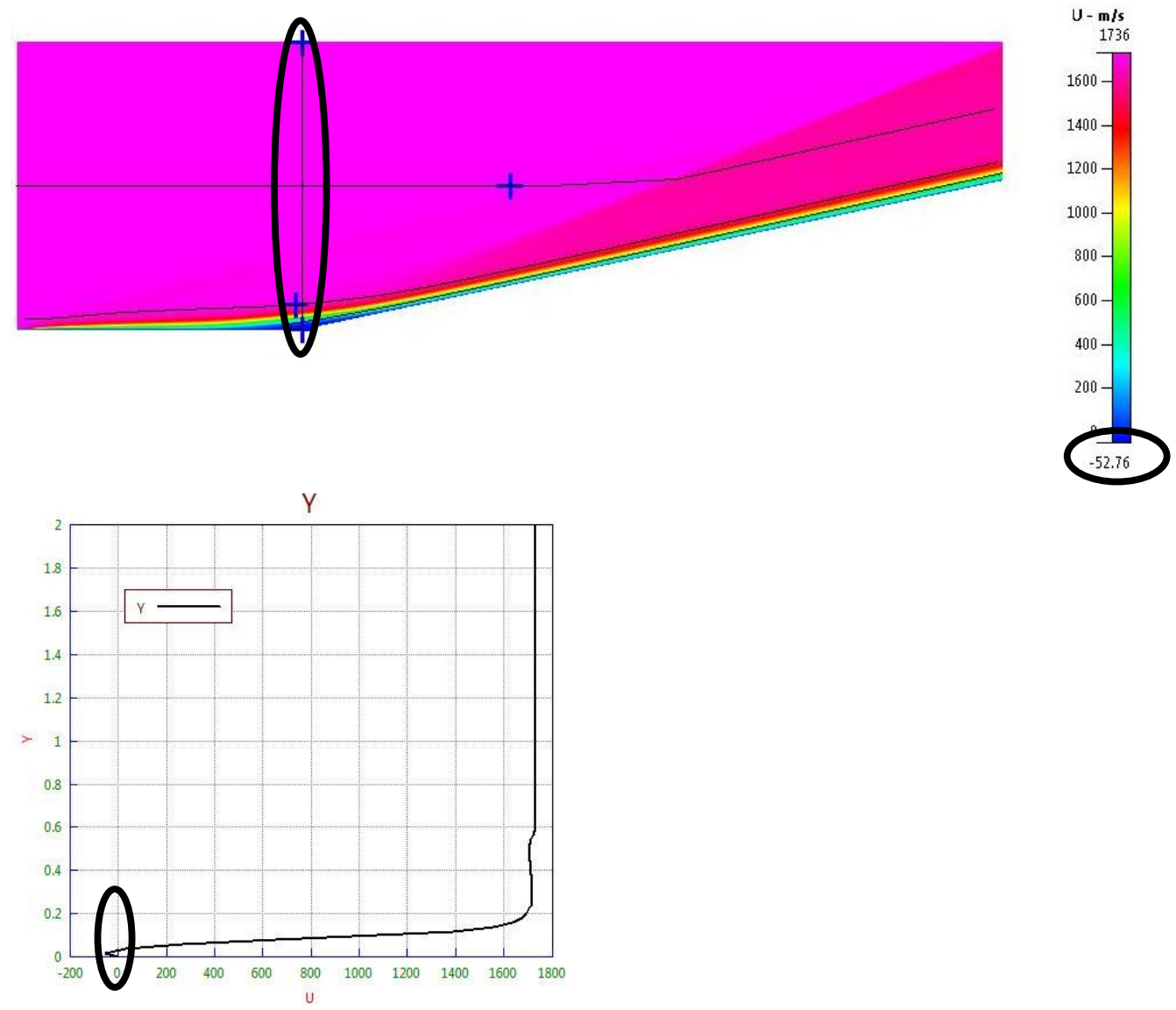

Figure 35 - Velocity profile 
Figure 36 is the magnified view of the boundary layer in Figure 35. The streamlines are added to view the direction of the flow. Figure 36 shows the streamline is turned upward and hugs tightly to the boundary layer. Furthermore, at the separated region at the corner, the streamline curves backward before it follows the main path. The backward curve indicates that the flow is separated at the corner and is reattached as it is traveling further.

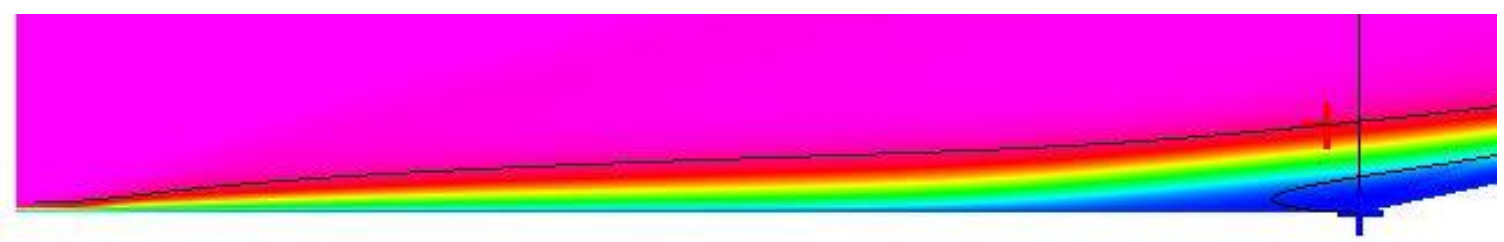

Figure 36 - Streamline

Figure 37 proves that the turbulent flow stays attached longer than the laminar flow. For the same turning angle and the same Mach number, the turbulent flow has no reversed flow while the laminar flow has a slightly reversed flow at the corner. The reversed flow can be shown by looking at the color key. The lowest velocity for the turbulent flow is zero, and the lowest velocity for the laminar flow is a negative value. Figure 38 is the magnified view at the separated region of the laminar flow. Even though the separated flow is very small, it occurs at the lowest region above the wall. Furthermore, looking at the boundary layers, turbulent flow has a thicker boundary layer. 

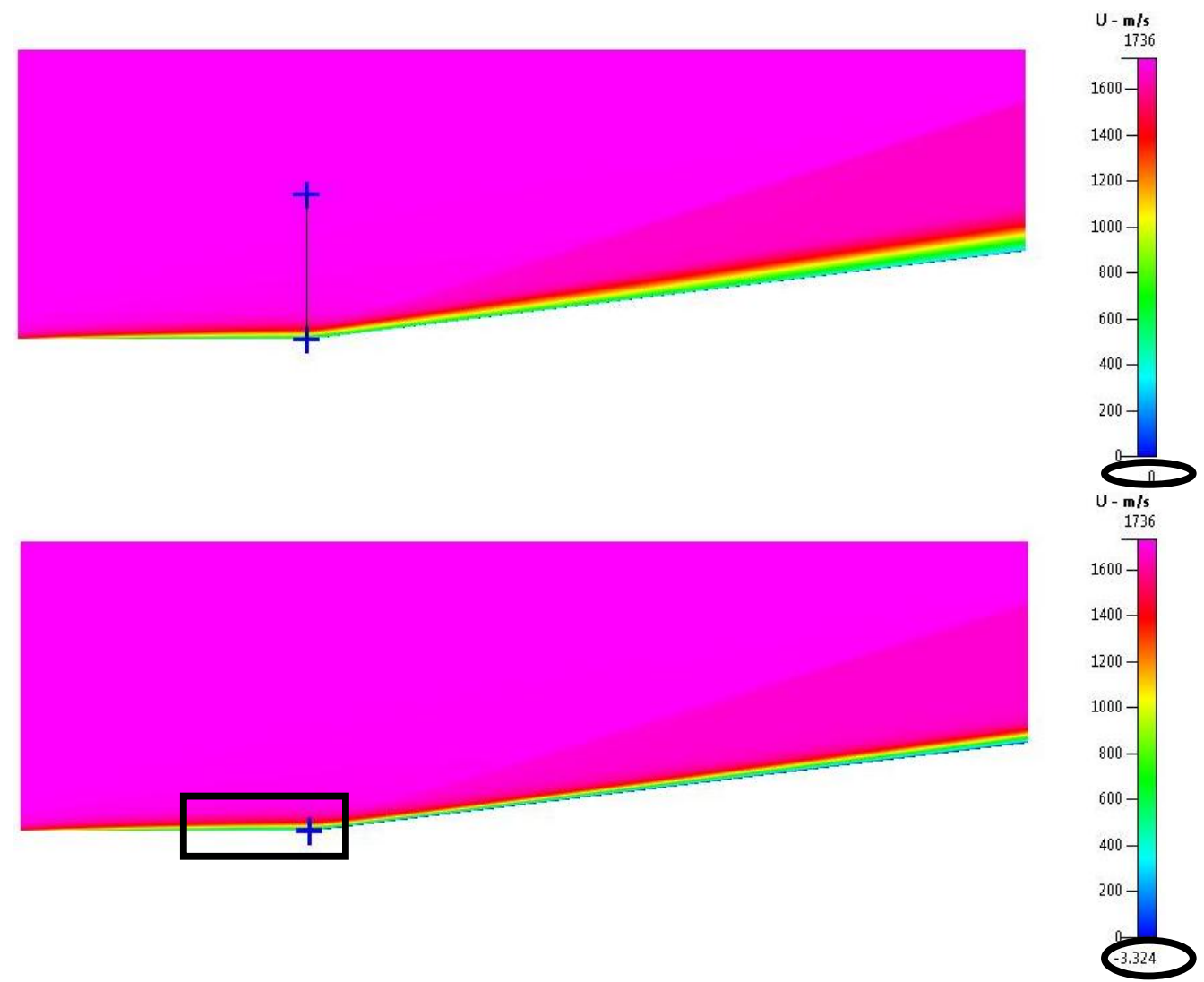

Figure 37 - Comparison of turbulent (top) and laminar (bottom) boundary layer

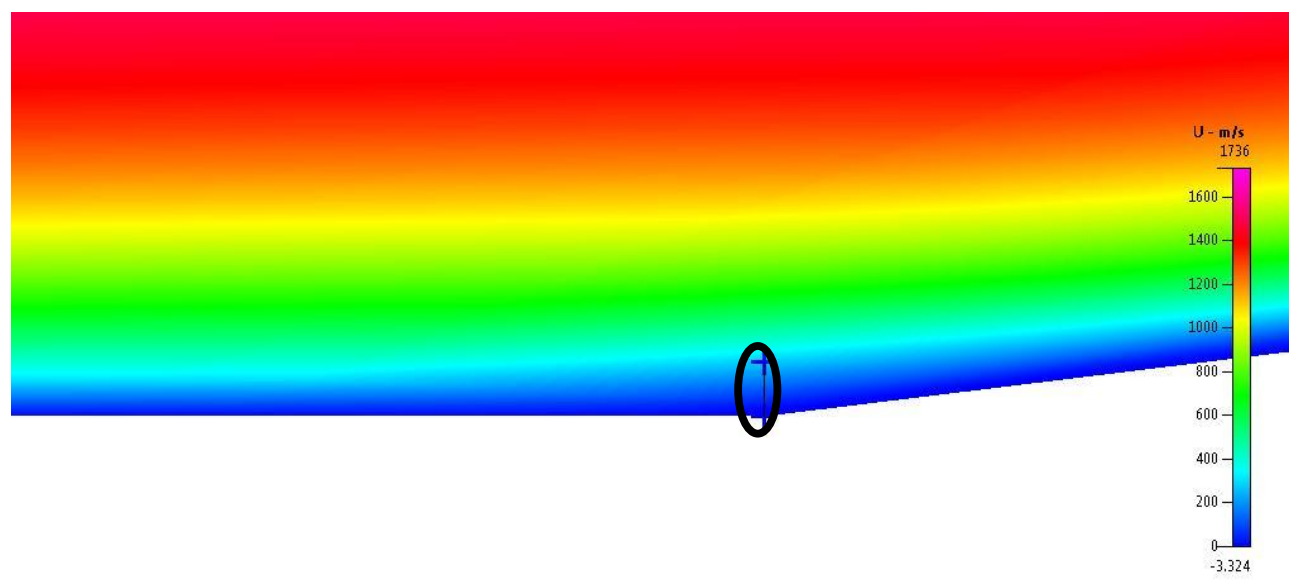

Figure 38 - Laminar flow's separation region (zoomed) 


\section{Conclusion}

The physics from the simulation results agree with the theory. When the flow reaches the compression corner, oblique shock occurs, making the Mach number decrease and the temperature and pressure increase. When the flow reaches the expansion corner, the expansion wave occurs; the Mach number increases, and the temperature and pressure decrease. The analytical results validate the computational results. Increasing the Mach number decreases the wave angle for both the compression and expansion corners. In the cases of the compression corners, the higher Mach number results in higher pressure and temperature while yielding lower pressure and temperature for the expansion corners. A higher turning angle increases the wave angle, pressure, and temperature for the compression corners and increases the Mach number and decreases the pressure and temperature for the expansion corners. Additionally, viscosity adds many complexities to the simulations. The formation of the boundary layer causes the flow to undergo a shock before it reaches the corner. The viscous flow is mostly concentrated on the compression corner because the turbulence is reduced by the favorable pressure gradient in the expansion corner. Tables and graphs are generated to show how the laminar flow and turbulent flow are different from the inviscid flow. The viscosity may also add separation to the flows, which can be determined by looking at the velocity profile at the corner. At a high turning angle, the flow may become separated. However, the turbulent flow can keep the flow attached better than the laminar flow. Overall, the simulation illustrates the physics by displaying the images of the distribution of the flow properties, such as the Mach number, temperature, and pressure. 


\section{References}

Anderson, J. D. (2007). Fundamentals of Aerodynamics. New York: McGraw-Hill.

Anderson, J. D. (2004). Modern Compressible Flow. New York: McGraw-Hill.

Bondarev, E. N. (1969). BOUNDARY-LAYER SEPARATION ON CONICAL BODIES. Mekhanika Zhidkosti i Gaza, 46-52.

Borovoi, V. Y., Egorov, I. V., Skuratov, A. S., \& Struminkaya, I. V. (2005). Effect of a High-Entropy Layer on Heat Transfer in the Region of the Incidence of an Oblique Shock Wave on a Blunted-Plate Surface. Doklady Physics, 3-6.

Dupont, P., Haddad, C., P., A. J., \& F., D. J. (2005). Space and time organisation of a shock wave/turbulent. Aerospace Science and Technology, 561-572.

Fedorova, N. N., \& A., F. I. (2004). COMPUTATIONS OF INTERACTION OF AN INCIDENT OBLIQUE SHOCK WAVE WITH A TURBULENT BOUNDARY LAYER ON A FLAT PLATE. Journal of Applied Mechanics and Technical Physics, 358-366.

Genin, F., \& Menon, S. (2010). Studies of shock/turbulent shear layer interaction using Large-Eddy Simulation. Computers \& Fluids, 800-819.

Knight, D., Yan, H., Panaras, A. G., \& Zheltovodov, A. (2003). Advances in CFD prediction of shockwave turbulent. Progress in Aerospace Sciences, 121-184.

Li, D. (2007, December 27). Shock reflection and oblique shock waves. Journal of Mathematical Physics.

Loomis, E., \& Swift, D. (2008, January 28). Oblique shock waves incident on an interface between two materials for general equation of state. Journal of Applied Physics.

Matyka, M. (2003). Prandtl-Meyer Expansion Wave. Computational Physics Section of Theoretical Physics at University Wroclaw in Poland.

Nakagawa, M., \& Harada, A. (2009). Analysis of Expansion Waves Appearing in the Outlets of Two-Phase Flow Nozzles. American Society of Heating, Refrigerating, and Air-Conditioning Engineers, Inc., 1065-1079.

Pasha, A. A., \& Sinha, K. (2008, September). Shock-unsteadiness model applied to oblique shock wave/turbulent boundary-layer interaction. International Journal of Computational Fluid Dynamics, pp. 569-582.

Walker, S., \& D., S. J. CFD Validation of Shock-Shock Interaction Flow Fields. Arlington: Research Technology Organization. 